NBER WORKING PAPER SERIES

\title{
ARE DYNAMIC VICKREY AUCTIONS PRACTICAL?: PROPERTIES OF THE COMBINATORIAL CLOCK AUCTION
}

\author{
Jonathan Levin \\ Andrzej Skrzypacz \\ Working Paper 20487 \\ http://www.nber.org/papers/w20487
NATIONAL BUREAU OF ECONOMIC RESEARCH
1050 Massachusetts Avenue
Cambridge, MA 02138
September 2014

We thank Chiara Farronato, Maarten Janssen, Paul Klemperer, Erik Madsen, David Salant and Ernesto Wandeler for useful comments and discussions. The authors have advised bidders and the U.S. Federal Communications Commission on radio spectrum auctions. The views expressed herein are those of the authors and do not necessarily reflect the views of the National Bureau of Economic Research.

At least one co-author has disclosed a financial relationship of potential relevance for this research. Further information is available online at http://www.nber.org/papers/w20487.ack

NBER working papers are circulated for discussion and comment purposes. They have not been peerreviewed or been subject to the review by the NBER Board of Directors that accompanies official NBER publications.

(C) 2014 by Jonathan Levin and Andrzej Skrzypacz. All rights reserved. Short sections of text, not to exceed two paragraphs, may be quoted without explicit permission provided that full credit, including (C) notice, is given to the source. 
Are Dynamic Vickrey Auctions Practical?: Properties of the Combinatorial Clock Auction Jonathan Levin and Andrzej Skrzypacz

NBER Working Paper No. 20487

September 2014

JEL No. D44,D47,D82,L51,L96

\section{ABSTRACT}

The combinatorial clock auction is becoming increasingly popular for large-scale spectrum awards and other uses, replacing more traditional ascending or clock auctions. We describe some surprising properties of the auction, including a wide range of ex post equilibria with demand expansion, demand reduction and predation. These outcomes arise because of the way the auction separates allocation and pricing, so that bidders are asked to make decisions that cannot possibly affect their own auction outcome. Our results obtain in a standard homogenous good setting where bidders have well-behaved linear demand curves, and suggest some practical difficulties with dynamic implementations of the Vickrey auction.

Jonathan Levin

Stanford University

Department of Economics

Stanford, CA 94305-6072

and NBER

jdlevin@stanford.edu

Andrzej Skrzypacz

Stanford University

Graduate School of Business

Stanford, CA 94305-5015

skrz@stanford.edu

A Online Appendix is available at

http://web.stanford.edu/ skrz/CCA\%20Levin\%20Skrzypacz\%20Appendix.pdf 


\section{Introduction}

In this paper we study some properties of a new auction design, the combinatorial clock auction (or CCA). The CCA was proposed by Ausubel, Cramton and Milgrom (2006). It is essentially a dynamic Vickrey auction. The Vickrey auction is central to economic theory as the unique auction that provides truthful incentives while achieving an efficient allocation. Yet it is often viewed as impractical for real-world applications because it requires bidders to submit bids for many possible packages of items. ${ }^{1}$ Economists think of dynamic auctions as having an advantage in this regard because bidders can discover gradually how their demands fit together — what Paul Milgrom has called the "package discovery" problem.

The CCA combines an initial clock phase, during which prices rise and bidders state their demands in response to the current prices, with a final round in which bidders submit sealed package bids. The seller uses the final bids to compute the highest value allocation and the corresponding Vickrey payments. ${ }^{2}$ Ideally, bidders demand their most desired package at every stated price in the clock phase, allowing for information revelation. Then in the final round, they bid their true preferences, leading to an efficient allocation with truthful Vickrey prices. The question we address is whether this is the likely equilibrium outcome of the CCA; that is, whether the desirable incentive properties of the Vickrey auction are retained.

The practical motivation for our study is the recent and widespread adoption of CCA bidding to sell radio spectrum licenses. ${ }^{3}$ Spectrum auctions have provided the motivation for some important recent innovations in auction design, starting with the simultaneous ascending auction pioneered by the FCC in the early 1990s and subsequently adopted in many other countries (Klemperer, 2004; Milgrom, 2004). The FCC design allows for gradual information revelation, but it does not easily accommodate package bidding, and it creates incentives for demand reduction because winners pay their bids (Cramton, 2013). In principle, the CCA addresses both of these issues.

As it turns out, the CCA does have an equilibrium in which bidding is truthful and the outcome is efficient. But it is a rather tenuous equilibrium. To support it, each bidder must behave "just

\footnotetext{
${ }^{1}$ Ausubel and Milgrom (2006) offer additional reasons why sealed-bid Vickrey auctions have not caught on in practice, including vulnerability to collusion even by losing bidders, incentives for shill bidding, and the potential for low revenue.

${ }^{2}$ The original CCA of Ausubel, Cramton and Milgrom (2006) and the rules used in practice actually call for a slight modification of Vickrey pricing, where the Vickrey prices are adjusted upwards if the outcome is outside the core. This "core-adjustment" will not be relevant in our model, but in general it means the truth-telling properties of the Vickrey auction may not apply. For papers on core-adjustment see for example Day and Raghavan (2007), Day and Milgrom (2008), Edril and Klemperer (2009), Ausubel and Baranov (2010), Beck and Ott (2013) or Goeree and Lien (2013).

${ }^{3}$ Countries that have used CCAs to sell radio spectrum licenses include Australia, Austria, Canada, Denmark, Ireland, the Netherlands, Switzerland, and the UK.
} 
right" when selecting between many final bids that lead to the exact same individual payoff. This indeterminacy may be surprising given the dominant strategy incentive properties of the Vickrey auction. It stems from the CCA activity rules that link final bids to earlier clock phase bids. In a dynamic auction, activity rules are essential in order to make early bids meaningful, and to prevent bidders from holding back their demand like eBay snipers (Ausubel, Cramton and Milgrom, 2006). The CCA activity rules have the feature that the clock phase bids can pin down exactly the allocation of items (Ausubel and Cramton, 2011; Ausubel and Baranov, 2013). Then the final bids determine the payments. But with Vickrey pricing, a bidder cannot affect her own payment unless she changes the allocation. So each bidder may be completely indifferent across her permissible final bids, despite the choice affecting the prices paid by rivals.

We explore the implications in a series of steps. We focus on a standard allocation problem where bidders have linear downward sloping demand curves. We first show that depending on how bidders resolve their final round indifference, the CCA can have many ex post equilibria. These equilibria involve varying degrees of strategic demand expansion in the clock phase, and no guarantee of efficiency. The multiplicity arises even though we focus on (linear) "proxy" strategies in which bidders do not condition their bids on rival bidding behavior. That is, we do not allow for bootstrapped equilibria of the type that are common in many dynamic games. Instead the source of multiplicity is the flexibility that bidders have to set each other's prices, and the lack of incentives to do so in any particular way. These points are developed in Sections 2-5, with Section 4 providing some empirical evidence on bidding in recent CCAs for radio spectrum.

We then ask what happens if bidders resolve their indifference in favor of making their rivals pay more. This resolves the final round indifference problem. In the class of linear proxy strategies it leaves only the equilibrium in which both bidders bid truthfully and the outcome replicates the sealed-bid Vickrey auction. However, if bidders truly want to raise rival prices without affecting their own payoffs, there are new problems in the clock phase. Our second analysis, in Section 6, shows that if bidder 1 bids truthfully, bidder 2 can adopt a non-proxy predatory strategy that exaggerates her demand in the clock phase. This relaxes her activity constraints and allows her to submit higher final bids that raise bidder 1's payment, all without affecting her own profit. If bidder 1 understands this, her best response is to reduce demand, leading to an equilibrium that skews the allocation in favor of the predatory bidder.

Finally, our third analysis considers what happens if both bidders try to raise each other's prices by relaxing the activity rule constraints on their final bids. This appears to have happened in at least one recent large-scale auction. We show in Section 7 that this leads to another multiplicity 
of ex post equilibria. These equilibria feature demand reduction in the clock phase, again with no guarantee of efficiency. Indeed in the limiting case of maximal aggressiveness, the bidders anticipate that they will pay linear clock prices, so the auction effectively becomes a standard ascending clock auction.

Our paper relates to an extensive literature on multi-item auctions (e.g. Milgrom, 2004). One of its central messages is that multi-item auction design involves hard trade-offs. The standard auctions that have been considered - simultaneous ascending and clock auctions, pay-as-bid combinatorial auctions - have well-documented limitations. In this sense, it is hardly surprising that the CCA also appears to have some drawbacks from a strategic perspective. In fact, one point we emphasize in the conclusion is that our analysis highlights a serious challenge for any attempt to implement a dynamic Vickrey auction, namely that it may be difficult to provide incentives for bidders to submit truthful bids for packages that they are very unlikely to win, despite these bids potentially being important for setting rival prices.

More narrowly, the novelty of the CCA design means there are not many directly related papers. The closest is Janssen and Karamychev (2013), who analyze bidding incentives in a CCA with discrete quantities and multiple products. They show that when bidders have preferences for raising rivals' costs (modeled similarly to what we do in Section 6), bidders have an incentive to submit large final round bids and bid aggressively in the clock phase. They also discuss how budget constraints can lead to non-truthful bidding. Salant (2013) provides a broader review of practical issues in auction design that covers the CCA as well as competing formats. ${ }^{4}$

\section{The Combinatorial Clock Auction}

The combinatorial clock auction can be used with multiple bidders and multiple products in different quantities. For concreteness, we will assume there are two bidders, $i=1,2$, and a single product. The product is perfectly divisible and there is unit supply.

The auction consists of an initial clock phase and a final bid round. In the clock phase, the seller gradually increases the price $p$. In response, the bidders announce demands $x_{1}, x_{2}$. A bidder may reduce her demand, but not increase it, as the auction proceeds. The price increases until there is no excess demand. If at this point $\sum_{i} x_{i}=1$, we say there is market clearing. Alternatively if $\sum_{i} x_{i}<1$, there is excess supply. Our analysis will focus on the case where the starting price is low and bidders reduce their demands continuously, so there is never excess supply.

\footnotetext{
${ }^{4}$ Additionally, Knapek and Wambach (2012) discuss why bidding in a CCA may be strategically complicated; Bichler et.al. (2013) present experimental results on the CCA.
} 
After the clock phase, the bidders submit final (sealed) bids $S_{1}\left(x_{1}\right)$ and $S_{2}\left(x_{2}\right)$. The seller computes the allocation and winner payments based on these final bids. She selects the allocation that maximizes $\sum_{i} S_{i}\left(x_{i}\right)$ subject to the feasibility constraint that $\sum_{i} x_{i} \leq 1$. She then computes the Vickrey payment for each bidder $i$. Bidder $i$ 's Vickrey payment is $\max _{x \in[0,1]} S_{j}(x)-S_{j}\left(x_{j}^{*}\right)$, where $x_{j}^{*}$ is $j$ 's winning quantity. ${ }^{5}$ If $S_{j}$ is increasing, $i$ pays $S_{j}(1)-S_{j}\left(x_{j}^{*}\right)$.

The final bids are constrained by an activity rule that ties them to bids in the clock phase. The activity rule we describe corresponds to those used in recent CCA auctions. ${ }^{6}$ It has three parts. First, bids in the clock phase are binding. If at price $p$, bidder $i$ demanded $x$, then bidder $i$ 's final bid for $x$ units must be at least $p x$, i.e. $S_{i}(x) \geq p x$. Second, final bids must satisfy revealed preference with respect to the last clock bids. If the clock phase ends at a price $p^{*}$, with $i$ demanding $x_{i}^{*}$, then for any $x \neq x^{*}, S_{i}(x)-p^{*} x \leq S_{i}\left(x^{*}\right)-p^{*} x^{*}$. Third, for quantities $x \geq x^{*}, i$ 's final bids must satisfy an additional local form of revealed preference. If $p$ was the highest price at which $i$ demanded $x$ or more units, then $i$ cannot express an incremental value greater than $p$ for obtaining slightly more than $x$, i.e. $\lim _{\varepsilon \rightarrow 0^{+}} \frac{S_{i}(x+\varepsilon)-S_{i}(x)}{\varepsilon} \leq p .{ }^{7}$ We illustrate these rules below.

The activity rule has an important implication. Suppose the clock phase ends with market clearing. Then the final clock demands will be value-maximizing for any permissible final bids! To see why, let $x_{1}^{*}, x_{2}^{*}$ be the final clock demands. Consider an alternative assignment where each bidder $i$ receives $x_{i}=x_{i}^{*}+\varepsilon_{i}$, with $\sum_{i} \varepsilon_{i} \leq 0$ required for feasibility. From the second activity rule requirement,

$$
\sum_{i} S_{i}\left(x_{i}\right) \leq \sum_{i} S_{i}\left(x_{i}^{*}\right)-p^{*} \cdot\left(x_{i}^{*}-x_{i}\right)=\sum_{i} S_{i}\left(x_{i}^{*}\right)+p^{*} \cdot \sum_{i} \varepsilon_{i} \leq \sum_{i} S_{i}\left(x_{i}^{*}\right) .
$$

This has the following consequence noted by Ausubel and Cramton (2011). If the clock phase ends with market clearing and ties are resolved in favor of the clock phase allocation, bidder $i$ 's quantity and payment do not depend on her final bids. The payment part follows from Vickrey pricing: fixing $i$ 's quantity, her payment depends only on the bids of others. Therefore if a bidder is maximizing her own individual profit she will be completely indifferent across all permissible final

\footnotetext{
${ }^{5}$ Here we implicitly assume a zero reserve price, but positive reserve prices are easily incorporated by adding a "bidder 0" that bids $S_{0}(x)$ where $S_{0}(1)-S_{0}(x)$ is the required revenue to sell $1-x$ units.

${ }^{6}$ It is exactly the rule used in Canada, and equivalent to the rules used in Switzerland, Ireland, Netherlands, and UK if those auctions had been run for only a single category of licenses. The exact rules used in these auctions vary somewhat in how they handle multiple license categories.

${ }^{7}$ An obvious candidate for an activity rule would be to require global revealed preference. That is, if $i$ demanded $x$ at price $p$, then for any $z \neq x$, final bids must satisfy $S_{i}(x)-p x \geq S_{i}(z)-p z$. In our model, this rule would impose what we later will call consistent bidding. However, as noted by Ausubel and Cramton (2011), such an approach seems unworkable with multiple categories because it can lead to "dead ends". In response to this, Ausubel and Baranov (2013) have suggested a new global approach based on GARP. We discuss their proposal in the conclusion.
} 
bids. However, these bids are very important for pricing, as we now show.

\section{An Illustrative Example}

We use an example to illustrate the CCA rules and resulting incentives. We first show how the activity rules permit a given bidder, here bidder 2, to make a range of final bids for any clock phase behavior. Then we show how bidder 2's choice of final bid affects bidder 1's total payment and the marginal prices he faces for additional units. These marginal prices in turn affect bidder 1's incentives in the clock phase, where the allocation is determined. Finally, we preview our results on predatory bidding by showing how bidder 2 can exaggerate her clock phase demand to relax her activity constraints and further raise bidder 1's payment.

For this example, we assume that during the clock phase bidder 2 behaves as if she has a value for $x_{2}$ units equal to $V_{2}\left(x_{2}\right)=2 x_{2}-\frac{1}{2} x_{2}^{2}$, and a diminishing marginal value $v_{2}\left(x_{2}\right)=2-x_{2} \cdot{ }^{8}$ When the price is $p$, she demands $x_{2}(p)=2-p$ units irrespective of bidder 1's behavior. The quantity $1-x_{2}(p)$ is the residual supply available to bidder 1 at price $p$. Assume the clock price starts at $p=1$. It rises so long as bidder 1 demands $x_{1}(p)>1-x_{2}(p)$, and stops as soon as $x_{1}(p) \leq 1-x_{2}(p)$. Suppose the clock phase ends at a price $p^{*}$ with bidder 2 demanding $x_{2}^{*}=2-p^{*}$, and bidder 1 demanding $x_{1}^{*}=1-x_{2}^{*}$. From above, we know the allocation $x_{1}^{*}, x_{2}^{*}$ will be the final auction result for any permissible final bids.

Despite the allocation being pinned down, bidder 2 has considerable flexibility in her final bids. Figure 1 illustrates the possibilities. The lower curve shows the bids that bidder 2 submitted during the clock phase. As the price rose, bidder 2 reduced her demand continuously from 1 to $x_{2}^{*}$. For quantities above $x_{2}^{*}$, bidder 2 demanded $x_{2}$ units when the price was $p=v_{2}\left(x_{2}\right)$. When she did this, she submitted a bid of $x_{2} v_{2}\left(x_{2}\right)$ for $x_{2}$ units. This bid is less than the value function $V_{2}\left(x_{2}\right)$ that guided bidder 2's clock phase bidding. In particular, the auctioneer records the revenue from bidder 2's bid at price $p=v_{2}\left(x_{2}\right)$, but not her consumer surplus. For quantities below $x_{2}^{*}$, bidder 2 has not recorded any bid during the clock phase, so her bid is zero.

The activity rule states that bidder 2's final bid $S_{2}$ must lie everywhere above the bids she recorded during the clock phase. Also, above $x_{2}^{*}$ the final bid function cannot rise more steeply than $V_{2}$. It must satisfy the local revealed preference restriction: $S_{2}^{\prime}\left(x_{2}\right) \leq v_{2}\left(x_{2}\right)$. So at the upper extreme, bidder 2 can raise her bids to the dashed curve, which rises at a slope $v_{2}\left(x_{2}\right)$ from her

\footnotetext{
${ }^{8}$ For this example it is not important whether $V_{2}$ is bidder 2's actual valuation. In our equilibrium analysis in Section 5 , bidders generally will not bid truthfully in the clock phase.
} 
final clock bid. ${ }^{9}$ The shaded area in Figure 1 shows that space in which the final bid function must lie, for quantities above $x_{2}^{*}$. Below $x_{2}^{*}$, bidder 2 may submit any non-negative bid $S_{2}$ so long as it lies below the dotted line with slope $p^{*}$ that runs straight from the origin to bidder 2's final clock bid. These bids, however, are not important for pricing. ${ }^{10}$

We say that bidder 2 is consistent if she raises her final bid above $x_{2}^{*}$ to its maximum amount. When she does this, the marginal values she expresses with her final bid correspond exactly to her inverse demand in the clock phase. In contrast, we say that bidder 2 is quiet if she does not raise her bids at all, so that $S_{2}\left(x_{2}\right)=x v_{2}\left(x_{2}\right)$. Under quiet bidding, $S_{2}$ corresponds to the revenue generated by bidder 2's clock phase demand, and the slope of $S_{2}$ is the marginal revenue associated with assigning more units to bidder 2, rather than the marginal values implicit in bidder 2's clock demand. In addition to consistent and quiet bidding, there are intermediate cases as well, since in the range $x_{2} \geq x_{2}^{*}$ (Region II in the figure), bidder 2 can select any $S_{2}\left(x_{2}\right)$ that lies in the shaded area and rises less steeply than $V_{2}\left(x_{2}\right)$.

Next we explain how bidder 2's choice will affect both the total payment by bidder 1 , and the marginal price he must pay for additional units. For simplicity, assume $S_{2}$ is increasing as it will be under both quiet and consistent bidding. Then bidder 1 must pay $S_{2}(1)-S_{2}\left(x_{2}^{*}\right)$ - bidder 2's bid for all units minus her bid for the units she wins. This amount is higher if bidder 2 is consistent than if she is quiet. So is bidder 1's marginal price for additional units. To see this, assume $S_{2}$ is differentiable and define $S_{2}^{\prime}\left(x_{2}\right)=s_{2}\left(x_{2}\right)$. Writing bidder 1's payment as $\int_{x_{2}^{*}}^{1} s_{2}\left(x_{2}\right) d x_{2}$, we can see that bidder 1's price for his final unit equals bidder 2's marginal bid for this unit, $s_{2}\left(x_{2}^{*}\right)$. Under consistent bidding $s_{2}\left(x_{2}\right)=v_{2}\left(x_{2}\right)$. Under quiet bidding $s_{2}\left(x_{2}\right)=\frac{d}{d x_{2}} x_{2} v_{2}\left(x_{2}\right)$. Consistent bidding means that bidder 1 must pay the clock price at which bidder 2 gave up the final unit. Quiet bidding means that bidder 1 must pay only the (smaller) marginal revenue reduction!

The marginal prices are important for clock phase incentives because the clock phase is where quantities are determined. Figure 2 illustrates the marginal prices faced by bidder 1 under consistent and quiet bidding. The $x$-axis shows the allocation: as we move to the right, we increase $x_{1}$ and decrease $x_{2}$. The $y$-axis is dollars. The solid green line plots the values $v_{2}\left(x_{2}\right)$ that guide bidder 2 's clock phase demand. At $p=v_{2}\left(x_{2}\right)$, bidder 2 demands $x_{2}$ units and the auctioneer records a

\footnotetext{
${ }^{9}$ Our discussion presumes that bidder 2 does not increase her clock bid for $x_{2}^{*}$, i.e. sets $S_{2}\left(x_{2}^{*}\right)=x_{2}^{*} v_{2}\left(x_{2}^{*}\right)$. We will assume this throughout for simplicity. If bidder 2 raises her bid for $x_{2}^{*}$ by $\Delta$ she is permitted to translate all her bids up by this same amount, so there is an analogue of quiet and consistent bidding for any choice of $\Delta$. Of course, if bidder 2 raises her bid for $x_{2}^{*}$, but does not raise her other bids, then bidder 1 could end up paying very little, and in fact pays zero if $S_{2}$ achieves its maximum at $x_{2}^{*}$. We mention below the possibility that bidder 2's final bids might be chosen in a way that drives down bidder 1's payment relative to quiet bidding, but will not focus on it.

${ }^{10}$ That is because the activity rule prevents bidder 2 from claiming to value $x_{2}<x_{2}^{*}$ more than she values $x_{2}^{*}$. So the maximum of $S_{2}$ will be achieved at a quantity $x_{2} \geq x_{2}^{*}$.
} 
bid $x_{2} v_{2}\left(x_{2}\right)$. The dotted line in Figure 2 shows how the recorded bid changes with $x_{2}$, i.e. it is the marginal revenue curve $m_{2}\left(x_{2}\right)$ associated with bidder 2's demand. If bidder 2 is quiet in the final round, this curve represents the marginal prices at which bidder 1 can purchase additional units. If bidder 2 is consistent, the marginal prices are given by the solid demand curve.

Now consider how bidder 1 should behave in the clock phase. We assume for concreteness that bidder 1 has value $U_{1}\left(x_{1}\right)=2 x-\frac{1}{2} x_{1}^{2}$ for $x_{1}$ units, and diminishing marginal value $u_{1}\left(x_{1}\right)=2-x_{1}$. Given bidder 2's assumed behavior, bidder 1 can purchase any quantity $x_{1}$ by demanding this amount in the clock phase when $p=v_{2}\left(1-x_{1}\right)$. Fixing bidder 2's final bid strategy $S_{2}$ (and assuming it is increasing), the optimization problem faced by bidder 1 is

$$
\max _{x_{1} \in[0,1]} U_{1}\left(x_{1}\right)-\left[S_{2}(1)-S_{2}\left(1-x_{1}\right)\right]
$$

If bidder 1 expects bidder 2 to be consistent, he expects to pay $S_{2}(1)-S_{2}\left(1-x_{1}\right)=\int_{1-x_{1}}^{1} v_{2}(x) d x$ for $x_{1}$ units. The marginal price for the $x_{1}$ th unit is $v_{2}\left(1-x_{1}\right)$, so he should purchase $x_{1}=1 / 2$, the quantity at which his marginal value $u_{1}\left(x_{1}\right)$ just equals his marginal price $v_{2}\left(1-x_{1}\right)$. Figure 2 shows how bidder 1 can achieve this outcome by bidding truthfully in the clock phase. If bidder 1 is truthful, his demand will intersect the residual supply available to him when $u_{1}\left(x_{1}\right)=p=$ $v_{2}\left(1-x_{1}\right)$.

In contrast, if bidder 1 expects bidder 2 to be quiet, the marginal price for his $x_{1}$ th unit is $m_{2}\left(1-x_{1}\right)$. So he should purchase up to the point at which $u_{1}\left(x_{1}\right)=m_{2}\left(1-x_{1}\right)$, i.e. $x_{1}=2 / 3$. To do this, he must end the clock phase with $x_{1}=2 / 3$ and $x_{2}=1 / 3$. Figure 2 shows how he can do this by inflating his stated demand from $u_{1}\left(x_{1}\right)$ to $v_{1}\left(x_{1}\right) .{ }^{11}$ Here, bidder 1 does not want to be truthful. He wants to overstate his demand because when the residual supply is $1-x_{2}$, the clock price is $v_{2}\left(x_{2}\right)=2-x_{2}$, but the true marginal price is only $m_{2}\left(x_{2}\right)=2-2 x_{2}$ !

This example points to a key strategic issue in the CCA. On the one hand, the rules are such that if bidders care only about their own quantity and payment, they are completely indifferent across permissible final bids. On the other hand, the way this indifference is resolved is very important for determining rival payments and rival incentives in the clock phase. A bidder will want to behave truthfully in the clock phase if his rival uses a consistent final bid strategy, but overstate his clock demand if he anticipates a quiet final bid strategy. We expand on this point, and consider a wider range of strategic postures and equilibrium outcomes, in Section 5.

\footnotetext{
${ }^{11}$ In this example, bidder 1's optimal strategy is pinned down at only a single point. In the models we consider below, we will pin down optimal strategies everywhere by requiring that bidder 1's strategy be optimal for a range of possible values of bidder 2 , and vice versa.
} 
The example is also useful to demonstrate a final point, namely how bidder 2's clock demand for inframarginal units affects bidder 1's payment. We illustrate in Figure 3. The figure shows bidder 2's baseline clock demand, and bidder 1's truthful demand, which is optimal if bidder 2 is consistent. Bidder 1 expects to pay the shaded area under bidder 2's demand curve. But what happens if bidder 2 raises her demand? In particular, what if she demands all the units (i.e. sets $\left.x_{2}=1\right)$ until the clock price reaches $p=3 / 2$, before reducing demand to match her baseline bidding? If bidder 2's final bid is now consistent with this higher demand, bidder 1 should still be truthful in the clock phase. However, he must pay the dotted area as well. His payment doubles from $1 / 8$ to $1 / 4$ ! We will explore this type of predatory bidding behavior in Sections 6 and 7 , starting with the scenario where a single bidder inflates clock phase demand to raise her rival's payment, and then considering what happens if both bidders are predatory.

\section{Evidence on CCA Bidding Behavior}

Given the ambiguous nature of incentives, a natural question is whether data from past auctions can tell us more about bidder behavior. Either bidding data or summary reports are available for several CCA sales of radio spectrum licenses. This evidence suggests a striking degree of heterogeneity across bidders and across auctions. Some bidders have submitted minimal final round bids, as in the quiet strategy described above. Some have submitted final bids that express clear valuation increments and resemble the consistent strategy described above. Others seem to have followed strategies designed to make rivals pay prices that are close to the linear prices at the end of the clock phase, as in our predatory bidding example. ${ }^{12}$

\subsection{Early UK Auctions (2008)}

The United Kingdom held two early CCA sales in 2008: for spectrum licenses in the 10-40 GHz range and then for $\mathrm{L}$ Band licenses. The auctions had combined revenue of around $£ 10$ million. We have information on these sales from reports released by the UK government (Cramton, 2008a,b; Jewitt and Li, 2008). ${ }^{13}$

\footnotetext{
${ }^{12}$ We discuss evidence from five past auctions below. As we were finalizing this draft, bidding data was released from the Canadian $700 \mathrm{MHz}$ auction conducted in early 2014. Our preliminary analysis of the data further supports the claim that there can be a great deal of heterogeneity in bidder behavior. Of the three most active bidders, two (Bell Canada and Telus) submitted final bids for a large number of different license packages (close to 500) at essentially the maximum amount allowed by the activity rules, whereas the third (Rogers), which ended up paying much more for the licenses it won, submitted only a single final round bid, with which it increased its bid for its winning package.

${ }^{13}$ The UK government also published a note explaining how the bids in the $10-40 \mathrm{GHz}$ auction determined the winner payments: http://stakeholders.ofcom.org.uk/binaries/spectrum/spectrum-awards/completed-awards/10-
} 
In the 10-40 GHz auction, there were ten bidders competing for 27 available licenses. There was a fair amount of competition during the clock phase. The average demand across licenses was 2.2 in the initial bidding round, and it took 17 rounds to reach market clearing. However, there was relatively little activity in the final bid round, despite the fact that all ten bidders ending up winning licenses. Only two bidders submitted final round bids on large numbers of packages. In Cramton's (2008a) description of the auction, the others "simply increased their clock bids, and added a handful of supplementary [i.e. final] bids on packages closely related to their bids in the latter part of the $V_{4}$ [i.e. phase]." Moreover, as Jewitt and Li (2008) explain, "all but one of the bidders made their highest supplementary bid either on their final clock package, or on a subset of it." This is an extreme form of quiet bidding. Most bidders expressed zero (or in fact negative) value for incremental spectrum beyond what they actually won!

In the L Band auction, there were eight bidders and 17 licenses for sale. Bidders could demand arbitrary packages of these licenses. Again, there was a fair amount of competition in the clock phase. The average demand for the licenses in the first round was 3.8 and the market cleared after 32 rounds. Again, however, there was little activity in the final bid round. Six of the bidders submitted final bids on just zero, one or two packages (Cramton, 2008b). Only two bidders submitted significant numbers of final bids. So again, the behavior of most bidders could be described as quiet, and there seems to have been some of the same behavior flagged by Jewitt and Li above. For example, Cramton (2008b) writes: "It is difficult to understand why WorldSpace [which entered only two new final bids] did not enter a more complete set of supplementary bids. Based on its bidding in the clock stage, it would appear to value nearly any set of three small lots at its upper limit of $2,614 . "$

\subsection{UK 4G Auction (2013)}

The United Kingdom's subsequent auction for 800 and $2600 \mathrm{MHz}$ spectrum involved much more valuable licenses, with the auction generating over $£ 2$ billion in revenue. There were four $10 \mathrm{MHz}$ licenses and a $20 \mathrm{MHz}$ license available in the $800 \mathrm{MHz}$ band. There were also multiple licenses available at $2600 \mathrm{MHz}$.

Table 1 shows the number of distinct packages bid on by each bidder in the $52 V_{4}$ s, and subsequently in the final round. ${ }^{14}$ If a bidder bid for the same package in multiple $V_{4}$ s, we count it just

28-32-40-ghz-awards/baseprices.pdf

${ }^{14}$ The numbers in this section come from our own analysis of the bidding data, which is available at: http://stakeholders.ofcom.org.uk/spectrum/spectrum-awards/awards-archive/completed-awards/800mhz$2.6 \mathrm{ghz} /$ auction-data/ 
once in the first column; if a bidder bid for a package in the clock phase and raised the bid in the final round, it counts in both columns.

\begin{tabular}{lccccc}
\hline & \multicolumn{2}{c}{ Packages Bid } & \multicolumn{2}{c}{$\mathrm{MHz}$ Won } & \\
Bidder & Clock & Final & 800 & 2600 & Payment \\
\hline EE & 6 & 48 & 10 & 70 & $£ 589 \mathrm{M}$ \\
Niche (BT) & 7 & 89 & - & 20 & $£ 186 \mathrm{M}$ \\
H3G & 7 & 12 & 10 & - & $£ 225 \mathrm{M}$ \\
MLL & 8 & 8 & - & - & - \\
HKT & 8 & 8 & - & - & - \\
Telefonica & 7 & 6 & 20 & - & $£ 550 \mathrm{M}$ \\
Vodafone & 11 & 94 & 20 & 65 & $£ 791 \mathrm{M}$ \\
\hline \hline
\end{tabular}

Table 1. Bidding in the UK 800/2600 Auction

Two of the bidders, MLL and HKT, dropped their demands to zero during the clock phase. Two other bidders, Telefonica and H3G, were active throughout the clock phase but submitted just a few final round bids. In contrast, EE, Niche and Vodafone bid for large numbers of packages in the final round.

Figure 4 shows the full set of package bids submitted by Vodafone. The bars represent the amount of spectrum demanded in different bands, and the line above shows the amount of each bid. Vodafone submitted bids for essentially all combinations of licenses that involved $20 \mathrm{MHz}$ of low-frequency spectrum (the most it was allowed to bid for) and the most desirable high-frequency spectrum. The bids are highly systematic. Vodafone expressed a value for the $20 \mathrm{MHz}$ low-frequency block nearly equivalent to its value for two $10 \mathrm{MHz}$ blocks, and appears to have expressed clear incremental values for the high-frequency blocks.

The incremental values expressed in these final bids are consistent with Vodafone's demand reductions in the clock phase. For instance, in $V_{4} 37$, when the price was $£ 87.6$ million for each $10 \mathrm{MHz}$ license, Vodafone reduced demand from 4 to $3 \mathrm{C}$ band licenses. Later in its final round bidding, it expressed an incremental value of $£ 87.6$ million for a fourth $\mathrm{C}$ band license. Toward the end of the clock phase, Vodafone was bidding for $20 \mathrm{MHz}$ at $800 \mathrm{MHz}$ and $30 \mathrm{MHz}$ in band C, and reduced its demand from 7 to 5 to 4 to 3 and then to 0 licenses in band E. The prices at which it made the reductions are consistent with the final bids shown in Figure 4. In this sense, Vodafone appears to have bid in a way that approximates fairly closely the consistent behavior described above. 
Telefonica, which bid for similar amounts of spectrum during the clock phase, behaved very differently in its final round bidding. Figure 5 shows its complete set of package bids. Telefonica bid for 7 different packages in the $V_{4} \mathrm{~s}$. In the final round, it added four new packages (bids 14), raised its bid for two packages from the clock phase (bids 5-6), and left five clock phase bids unchanged (bids 7-11). The bids it left unchanged are dominated. They could not have been winning bids or mattered for rival prices as each is for a larger package than bid 4, and offers less money.

Telefonica's five meaningful bids were quite similar in terms of spectrum demanded and amount offered. Bid 2 was Telefonica's winning bid. So Telefonica expressed very little value for packages larger than what it won - the incremental values expressed in its final bids are much lower than the prices at which it reduced demand in the $V_{4} \mathrm{~S}$. In this sense, its bidding behavior was much closer to the quiet strategy described above than to consistent bidding.

\subsection{Austrian 4G Auction (2013)}

The Austrian 4G auction involved the sale of high-value spectrum licenses in the 800, 900 and $1800 \mathrm{MHz}$ bands. The only bidders were the three major wireless companies in Austria. Each was limited to bidding on no more than $50 \%$ of the available licenses. This still allowed any two bidders to submit a combined bid for all licenses in the auction, i.e. it did not imply that winners automatically received some spectrum at reserve prices.

The auction yielded revenue of just over $€ 2$ billion, which far exceeded forecasts. ${ }^{15}$ A report released by the regulatory authority after the auction cited aggressive final round bids as a key factor in the high prices paid by the winners: ${ }^{16}$ The report reads:

During [the final bid] stage every bidder was allowed to submit as many as 3,000 supplementary bids. (...) The three bidders actually submitted a total of more than 4,000 supplementary bids. More than $65 \%$ of these supplementary bids were submitted for the largest permissible combinations of frequency blocks, with a share of some $50 \%$ of available frequencies. In addition, the bidders utilised almost to the full the price limits that had applied to these large packages during the sealed-bid [i.e. final] stage. (...) These supplementary bids submitted on large frequency packages had a significant effect on the prices offered by the other bidders. At the same time, such bids generally only have a marginal likelihood of winning out in the end. If these bids for very large

\footnotetext{
${ }^{15}$ Press coverage after the auction quoted one industry CEO as saying that the high prices were "a bitter pill to swallow," and another as claiming that the outcome was "a disaster for the industry as a whole." (http://www.fiercewireless.com/europe/story/austrian-operators-file-complaints-over-spectrum-auction-800mhz-900-mhz-an/2013-11-27).

${ }^{16}$ The report, titled "Result of the 2013 multiband auction driven by consistently offensive bidding strategy on the part of all three contenders" is available at https://www.rtr.at/en/pr/PI28102013TK, along with a presentation containing the numbers quoted below.
} 
numbers of frequencies had been ignored when determining the winners and prices, the revenue from the auction would have settled at a level of about EUR 1 billion.

A remarkable feature of the Austrian auction is that the final revenue ended up quite close to the total license prices at the end of the clock phase, which were $€ 2.07$ billion. Had the bidders submitted no final round bids (i.e. been quiet), the winners would have paid $€ 765$ million. Instead they paid $€ 2.01$ billion. If bidding in both stages of the auction was truthful, average license prices under the Vickrey formula only would be as high as prices at the end of the clock phase if bidders were willing to pay for all their incremental spectrum at the same rate as for a marginal license.

In this sense, the pricing outcome in the Austrian auction resembles the predatory example at the end of the previous section, where a bidder could end up paying the full clock price for every unit. We explore the idea that bidders may strategically increase rival prices, and the implications of this behavior for equilibrium allocations and revenue, in Sections 6 and 7 below.

\section{Discounts and Demand Expansion}

In this section and the following ones, the basic environment is the same. There is a single unit to be allocated, perfectly divisible. There are two bidders, $i=1,2$. Each bidder $i$ has marginal value for an $x$ th unit given by $u_{i}(x)=a_{i}-b_{i} x$, where $a_{i} \geq b_{i}>0$. Bidder $i$ 's total value for $x$ units is $U_{i}(x)=\int_{0}^{x} u_{i}(z) d z=a_{i} x-\frac{1}{2} b_{i} x^{2}$. Throughout, we use lower case to denote marginal values and upper case to denote total values. We assume that the $a_{i}$ 's are private information and take values between $\left[\underline{a}_{i}, \bar{a}_{i}\right]$, while the $b_{i}$ 's are common knowledge. To avoid messy corner solutions, we assume that $\bar{a}_{i}-b_{i}<\underline{a}_{j}$. This means that the efficient allocation is always interior, and satisfies $u_{1}\left(x_{1}\right)=u_{2}\left(1-x_{1}\right)$.

A proxy strategy for bidder $i$ is described by a (continuous, positive and decreasing) marginal value function $v_{i}(x)$, and associated $V_{i}(x)$ that guides demand in the clock phase, and a final bid function $S_{i}(x)$ with associated marginal bid function $s_{i}(x)$ that guides behavior in the final bid round. In the clock phase, bidder $i$ demands quantity $x$ when $p=v_{i}(x)$ (if $p<v_{i}(1)$ bidder $i$ demands the whole supply). In doing so, she expresses a bid $x v_{i}(x)$ for $x$ units. In the final bid round, she bids $S_{i}(x)$ for all quantities $x$ demanded in the clock phase (bids for smaller quantities are irrelevant if there is market clearing in the clock phase). To satisfy the activity rule, the proxy values must satisfy, for all $x$ : (i) $S_{i}(x) \geq x v_{i}(x)$, and (ii) $s_{i}(x) \leq v_{i}(x) .{ }^{17}$

\footnotetext{
${ }^{17}$ We focus on proxy strategies in order to emphasize issues that are specific to the CCA. The CCA also admits a rich set of contingent or bootstrapped equilibria, in which bidder $j$ makes a certain demand in equilibrium because she believes that if she doesn't, bidder $i$ will punish her as the auction proceeds. However, these types of dynamics are familiar from other dynamic auctions and are not specific to the CCA.
} 
We restrict bidders to use proxy strategies and focus on equilibria in linear proxy strategies, in which each bidder bids a linear demand curve in the clock phase, and adopts a mixture of quiet and consistent behavior in the final round.

A linear proxy strategy for bidder $i$ specifies a linear demand for the clock phase

$$
v_{i}(x)=A_{i}-B_{i} x,
$$

with $A_{i} \geq B_{i}>0$, and associated marginal revenue curve

$$
m_{i}(x)=\frac{d}{d x} x v_{i}(x)=A_{i}-2 B_{i} x
$$

It also specifies a linear demand for the final bid round:

$$
\begin{aligned}
s_{i}(x) & =\left(1-\gamma_{i}\right) v_{i}(x)+\gamma_{i} m_{i}(x) \\
& =A_{i}-\left(1+\gamma_{i}\right) B_{i} x
\end{aligned}
$$

The parameter $\gamma_{i} \in[0,1]$ captures the extent to which bidder $i$ is consistent $(\gamma=0)$ versus quiet $(\gamma=1)$. Higher values of $\gamma_{i}$ mean lower marginal prices for bidder $j$, because $i$ is expressing less value for any particular unit. It is easy to see that for any value of $\gamma_{i}, s_{i}(x)$ satisfies the activity rule.

A linear proxy strategy requires the choice of three parameters: $A_{i}, B_{i}$ and $\gamma_{i}$. Provided the clock price starts sufficiently low, the clock phase will end with market clearing. So for any $A_{j}, B_{j}, \gamma_{j}$, bidder $i$ 's payoff will depend only on her choice of $A_{i}, B_{i}$, and will be independent of her choice of $\gamma_{i}$. Therefore to characterize equilibria, we fix $\gamma_{1}$ and $\gamma_{2}$ as parameters, and solve for equilibrium choices of $A_{1}, A_{2}, B_{1}, B_{2}$. We focus on equilibria that are "ex post" or "robust", in that for any $a_{i}$, the strategy adopted by bidder $i$ is a best response to $j$ 's strategy for every value of $a_{j} \in\left[\underline{a}_{j}, \bar{a}_{j}\right]$.

\subsection{Proxy Best Responses}

We start by deriving best responses for bidder 1 . We show that if bidder 2 uses a linear proxy strategy, where $A_{2}$ varies with her private information $a_{2}$, but $B_{2}$ and $\gamma_{2}$ do not, then bidder 1 always has an ex post best response that involves using a linear proxy strategy in which $A_{1}$ is the

only parameter to vary with $a_{1}$ (so that iterating on the best-response correspondence keeps us within this class of strategies).

Suppose bidder 2 bids according to $v_{2}(x)=A_{2}-B_{2} x$. If bidder 1 bids according to $v_{1}(x)$, and 
the clock allocation is interior, then bidder 1 obtains quantity $x_{1}$ such that

$$
v_{1}\left(x_{1}\right)=v_{2}\left(1-x_{1}\right)
$$

Then after the final bid round, bidder 1 will pay $S_{2}(1)-S_{2}\left(1-x_{1}\right)$. His final payoff will be:

$$
U_{1}\left(x_{1}\right)-\left[S_{2}(1)-S_{2}\left(1-x_{1}\right)\right]
$$

A necessary condition for bidder 1's strategy to be ex post optimal is that knowing $v_{2}$, he does not prefer to purchase a slightly larger or smaller quantity than $x$. The marginal benefit of additional quantity is $u_{1}(x)$, and the marginal price is $s_{2}(1-x)$. So a necessary condition for ex post optimality is that:

$$
u_{1}(x)=s_{2}(1-x)
$$

This condition is also sufficient for ex post optimality if it holds for all $v_{2}, x$ that satisfy (6). ${ }^{18}$

Substituting (6) into (8), and using the fact that bidder 2 is playing the linear proxy strategy $s_{2}(1-x)=v_{2}(1-x)-\gamma_{2} B_{2}(1-x)$, we obtain a best response for bidder 1 :

$$
v_{1}(x)=u_{1}(x)+\gamma_{2} B_{2}(1-x) .
$$

Therefore bidder 1 can follow the linear proxy strategy $v_{1}(x)=A_{1}-B_{1} x$, with

$$
A_{1}=a_{1}+\gamma_{2} B_{2} \quad \text { and } \quad B_{1}=b_{1}+\gamma_{2} B_{2},
$$

and this is a best response for every $a_{2}$.

\subsection{Proxy Equilibrium}

We now solve for an ex post equilibrium in linear proxy strategies. To do this, we combine the best response conditions (10) for bidders 1 and 2. Then, so long as $\gamma_{1}$ and $\gamma_{2}$ are not both equal to one,

$$
A_{1}=a_{1}+\frac{\gamma_{2}\left(\gamma_{1} b_{1}+b_{2}\right)}{1-\gamma_{1} \gamma_{2}} \equiv a_{1}+\lambda_{1}
$$

\footnotetext{
${ }^{18}$ This is because, given $v_{2}$, bidder 1's global best response problem is first to choose $x_{1}$ that maximizes $U_{1}(x)-$ $\left\{\max _{y} S_{2}(y)-S_{2}(x)\right\}$, which is a concave problem, and then choose some decreasing $v_{1}$ such that $v_{1}\left(x_{1}\right)=v_{2}\left(1-x_{1}\right)$. Moreover, by this reasoning, the strategies we characterize remain best responses even if we remove the restriction to continuously-decreasing proxy strategies. For example, even if bidders could drop demand discontinuously to end the clock phase with excess supply, they would not find it profitable.
} 
and

$$
B_{1}=b_{1}+\frac{\gamma_{2}\left(\gamma_{1} b_{1}+b_{2}\right)}{1-\gamma_{1} \gamma_{2}} \equiv b_{1}+\lambda_{1}
$$

Proposition 1 Fix any $\gamma_{1}, \gamma_{2} \in[0,1]$ with $\gamma_{1} \gamma_{2}<1$. The CCA has an ex post equilibrium in linear proxy strategies, in which bidder $i$ bids according to $v_{i}(x)$ in the clock phase and $s_{i}(x)$ in the final round, with

$$
\begin{aligned}
v_{i}(x) & =u_{i}(x)+\lambda_{i}(1-x), \\
\text { and } s_{i}(x) & =v_{i}(x)-\lambda_{j} x,
\end{aligned}
$$

where $\lambda_{i}=\frac{\gamma_{j}\left(\gamma_{i} b_{i}+b_{j}\right)}{1-\gamma_{i} \gamma_{j}}$.

Remark 1 The above proposition describes equilibria for $\gamma_{1} \gamma_{2}<1$. What if both bidders are completely quiet? Then the best responses (10) imply $B_{1}=b_{1}+B_{2}$, and $B_{2}=b_{2}+B_{1}$. The system "explodes" as $\gamma_{1}=\gamma_{2} \rightarrow 1$ and there is no equilibrium. This non-existence is a consequence of assuming 2 bidders and is familiar from other models with linear demands (e.g., Kyle 1989 or Vives 2011). For example, adding to the model a small non-strategic third bidder would allow us to construct linear proxy equilibria even for $\gamma_{1}=\gamma_{2}=1$.

Figure 6 shows the optimization problem for bidder 1, for a fixed value of $a_{1}$, given that bidder 2 is playing her equilibrium strategy. For each realization of $a_{2}$, bidder 1 wants the clock phase to end with his marginal benefit for additional quantity $u_{1}\left(x_{1}\right)$ just equal to the marginal price $s_{2}\left(x_{2}\right)$. To make sure this happens, bidder 1 needs to have $v_{1}\left(x_{1}\right)=v_{2}\left(x_{2}\right)$ at the relevant $x_{1}, x_{2}$. Solving the optimization problem for each $a_{2}$ traces out bidder 1's optimal demand curve $v_{1}\left(x_{1}\right)$.

Figure 7 illustrates the equilibrium. It shows the equilibrium bids $v_{1}\left(x_{1}\right)$ and $v_{1}\left(x_{2}\right)$ for a particular realization of $a_{1}, a_{2}$, along with the final bids $s_{1}\left(x_{1}\right)$ and $s_{1}\left(x_{2}\right)$. (Note that as we did in Figures 2 and 3, we have drawn the marginal bids rather than the total bids.) As the clock price rises, the bidders reduce demand along their proxy demand curves $v_{1}\left(x_{1}\right)$ and $v_{2}\left(x_{2}\right)$ until reaching market clearing at $p^{*}$. At the end of the clock phase, the final allocation is determined to be $x_{1}^{*}, x_{2}^{*}$. Then the final bids are made. Bidder 1 pays $S_{2}(1)-S_{2}\left(x_{2}^{*}\right)=\int_{x_{2}^{*}}^{1} s_{2}\left(x_{2}\right) d x_{2}$, which is the shaded area in the figure. The price bidder 1 pays for his last unit is $s_{2}\left(x_{2}^{*}\right)$.

\subsection{Properties of Equilibrium}

Bidding Behavior. The equilibrium involves bidders engaging in demand expansion during the clock phase because they perceive that their true marginal prices will be discounted from the clock 
price. To see this, consider bidder 1's behavior in an equilibrium with $\gamma_{2}>0$. The residual supply available to bidder 1 will be $x$ when the clock price is $p=v_{2}(1-x)$. Yet bidder 1's true marginal price for buying the $x$ th unit is less than $p$. It is equal to $s_{2}(1-x)=p-\lambda_{1}(1-x)$. The discount is greatest if bidder 1 is buying a small quantity, and smaller for large quantities. The equilibrium response is to engage in demand expansion. Bidder 1's clock demand is higher than his true demand: $v_{1}(x)-u_{1}(x)=\lambda_{1}(1-x) \geq 0$. Following the logic above, the degree of demand expansion is largest for small quantities, and smaller for large quantities.

The one exception occurs if bidder 2 is consistent and $\gamma_{2}=0$. In this case the true marginal price that bidder 1 faces is the same as the clock price. So bidder 1's optimal strategy is to bid his true demand in the clock phase, $v_{1}(x)=u_{1}(x)$.

The relationship between a bidder's true demand and her final round demand is more complicated. Although bidder $i$ will engage in demand expansion in the clock phase if bidder $j$ is not consistent, she does not increase her final bids to match her clock demand provided that $\gamma_{i}>0$. Combining these offsetting forces,

$$
s_{i}(x)-u_{i}(x)=\lambda_{i}(1-x)-\lambda_{j} x
$$

Bidder $i$ 's final demand $s_{i}(x)$ is steeper than her true demand $u_{i}(x)$ and rotated around $\widehat{x}_{i}=$ $\lambda_{i} /\left(\lambda_{i}+\lambda_{j}\right)$.

Allocation and Revenue. The equilibrium allocation is generally not efficient and the revenue differs from what would occur in a Vickrey auction with truthful bidding. The main exception to this occurs if both bidders are consistent. If bidder 2 is consistent, the best response for bidder 1 is to bid truthfully, and vice-versa. So the clock phase allocates the items efficiently, and after the final bid round, each bidder pays its truthful Vickrey price.

More generally, we can obtain a fairly sharp characterization for symmetric equilibria in which $\gamma_{1}=\gamma_{2}=\gamma$ and $b_{1}=b_{2}=b$. In this case, bidder $i$ 's clock phase strategy is $v_{i}(x)=u_{i}(x)+$ $\frac{\gamma}{1-\gamma} b(1-x)$. Provided that $\gamma>0$, the equilibrium allocation will be distorted toward $1 / 2$ because a low-value bidder inflates her clock phase demand more than a high-value bidder. In particular, we can find the efficient allocation is obtained by setting $u_{1}\left(x_{1}\right)=u_{2}\left(1-x_{1}\right)$, which occurs at $x_{1}^{e}=\frac{1}{2}+\frac{a_{1}-a_{2}}{2 b}$. The equilibrium outcome $x_{1}^{*}$ solves $v_{1}\left(x_{1}\right)=v_{2}\left(1-x_{1}\right)$, which means

$$
x_{1}^{*}=\frac{1}{2}+\frac{a_{1}-a_{2}}{2 b}(1-\gamma)=\frac{1}{2} \gamma+(1-\gamma) x_{1}^{e} .
$$


It is also possible to show for the case of symmetric equilibria that the expected CCA revenue is decreasing in $\gamma$. Since the outcome with $\gamma=0$ corresponds to a Vickrey auction with truthful bidding, this means that every symmetric equilibrium that involves any degree of "quietish" final round bidding $(\gamma>0)$ generates lower expected revenue than a truthful Vickrey auction. The derivation of this result requires some calculations that we go through in the Appendix.

It is harder to obtain sharp characterizations for asymmetric equilibria. However, one particular case of interest occurs when one bidder is consistent while the other is partially quiet, e.g. if $\gamma_{1}>0$ and $\gamma_{2}=0$. In this case, bidder 1 bids his true demand in the clock phase, $v_{1}(x)=u_{1}(x)$, but does not fully raise his final bids. In contrast, bidder 2 expands her clock demand to $v_{2}(x)=$ $u_{2}(x)+\gamma_{1} b_{1}(1-x)$, and raises her final bids to this same demand. The result is that bidder 1 obtains a strictly smaller quantity in equilibrium than is efficient, $x_{1}^{*}<x_{1}^{e}$. It turns out, however, that the revenue comparison is ambiguous. In particular, we show in the Appendix that the expected CCA revenue for this type of asymmetric equilibrium can be either higher or lower than in a Vickrey auction with truthful bidding.

\section{Predatory Behavior}

Our first model emphasized that each bidder is indifferent between alternative final bids, yet her choice matters for how her opponent should behave in the clock phase. The result is that even if we restrict attention to relatively non-strategic proxy strategies, there are many equilibria involving varying amounts of demand expansion in the clock phase, to compensate for the price reductions offered in the final bid round. The equilibrium is generally not efficient, unless both bidders raise their bids fully in the final round.

Of course in practice, bidders may not be truly indifferent. They may care to some extent about rival payments. A bidder might benefit from raising rival costs, or from looking good relative to opponents. (See Janssen and Karamychev 2013 for further discussion and analysis of the bidding incentives when bidders care about relative prices as in this section. ${ }^{19}$ )

Suppose that each bidder still wants to maximize her own profit, but if she can raise her rival's payment without affecting the allocation or her own payoff, she will do so. Now both bidders will want to be consistent in their final bids. But will they want to be truthful in the clock phase? From above, the answer is yes if we restrict attention to proxy strategies. However, if bidder 1 is truthful in the clock phase and consistent in his final bidding, bidder 2 will have an incentive to depart from

\footnotetext{
${ }^{19}$ See also Morgan, Steiglitz and Reis (2003) and a subsequent literature of spiteful bidding in standard auctions.
} 
a proxy strategy and force her rival to pay higher prices. In particular, she can overstate her clock phase demand as in the last part of Section 3. We will show that if bidder 1 understands this, and continues to restrict himself to a proxy strategy, he will want to engage in demand reduction, leading to an inefficient outcome where the predatory bidder obtains an advantage.

\subsection{Proxy Bidding and Predatory Best Responses}

We now assume that the bidders care first about maximizing their own profit, and second about making rivals pay more. Under this assumption, both bidders will want to raise their final bids to the maximum allowed by the activity rules, and hence will be consistent. Additionally, we restrict bidder 1 to a proxy strategy in the clock phase. That is, bidder 1 bids according to $v_{1}(x)$ in the clock phase (which is continuous and weakly decreasing), and then demands $s_{1}(x)=v_{1}(x)$ in the final round. We allow bidder 2 to use any bidding strategy so long as she reduces demand continuously in the clock phase. To model this, we allow for the possibility that bidder 2 may drop her demand discretely, say from $x_{2}^{\prime}$ to $x_{2}$, at a given price $p$, but assume that if she does this, she offers to buy any intermediate quantity at that price. The last assumption ensures there will be market clearing. ${ }^{20}$

We have seen how bidder 2 can raise bidder 1's price in Section 3. Her most effective strategy is to keep her demand at 1 until the price $p$ and residual supply $1-x_{1}$ reach a level at which

$$
u_{2}\left(1-x_{1}\right)=p=v_{1}\left(x_{1}\right),
$$

and then reduce her demand to $1-x_{1}$ ending the auction. She can then submit her maximal final bid of $S_{2}(z)=p z$ for $z \geq 1-x_{1}$, and make bidder 1 pay the clock price for all $x_{1}$ units.

Why is this optimal for bidder 2? First, consider bidder 2's problem of maximizing her own profit. To buy $x_{2}$ units and obtain value $U_{2}\left(x_{2}\right)$ she must pay $S_{1}(1)-S_{1}\left(1-x_{2}\right)=V_{1}(1)-$ $V_{1}\left(1-x_{2}\right)$. So she wants to choose a quantity $x_{2}$ that maximizes:

$$
U_{2}\left(x_{2}\right)-\left[V_{1}(1)-V_{1}\left(1-x_{2}\right)\right]
$$

Therefore, her ex post optimal quantity is the unique solution to $u_{2}\left(x_{2}\right)=v_{1}\left(1-x_{2}\right)$. Moreover, conditional on buying $x_{2}$ units and ending the auction with market clearing, the most she can possibly make bidder 1 pay for his $x_{1}=1-x_{2}$ units is $x_{1} v_{1}\left(1-x_{1}\right)$, which she achieves.

\footnotetext{
${ }^{20}$ In particular, if bidder 1 is demanding $x_{1}$ at $p$ and $1-x_{1}$ is strictly between $x_{2}^{\prime}$ and $x_{2}$, then when bidder 2 drops her demand from $x_{2}^{\prime}$ to $x_{2}$, bidder 2 will be assigned $1-x_{1}$.
} 
Remark 2 If we allowed bidder 2 to create excess supply at the end of the clock phase, she could increase bidder 1 payment even more. For example, suppose bidder 1 follows a proxy strategy $v_{1}(x)=1-x$. Then, player 2 with valuation $u_{2}=1-x$ could demand $x_{2}=1$ until the price reaches (almost) 1 and then drop demand to $x_{2}=\frac{1}{2}$. She would then submit two supplementary round bids: $S_{2}(1)=1$ and $S_{2}\left(\frac{1}{2}\right)=\frac{5}{8}$. In this way the final allocation would be $\left(\frac{1}{2}, \frac{1}{2}\right)$ as in the best response we described above, but player 1 would end up paying his full value: $S_{2}(1)-S_{2}\left(\frac{1}{2}\right)=\frac{3}{8}=V_{1}\left(\frac{1}{2}\right)$. Such extreme predatory behavior is even more difficult to execute and even more risky for player 2 than what we describe. Moreover, analyzing equilibria in this case is difficult, so we maintain the assumption that player 2 is not allowed to create excess supply in the clock phase.

\subsection{Ex Post Equilibria with a Predatory Player}

How does bidder 2's predatory behavior affect the auction? Suppose bidder 1 is truthful, so that $v_{1}(x)=u_{1}(x)$. Then bidder 2's predatory behavior leads to the same efficient quantity outcome as if she also bid truthfully. However, bidder 1 pays the full market clearing clock prices, rather than the Vickrey payment. If bidder 1 understands this, and anticipates that he will pay the clock price for all of his units, he optimally responds by reducing demand.

For bidder 1 to purchase $x$, he must pay $x u_{2}(1-x)$. So bidder 1 would like to solve

$$
\max _{x} U_{1}(x)-x u_{2}(1-x)
$$

which gives a unique optimal $x$ that satisfies

$$
u_{1}(x)=u_{2}(1-x)-x u_{2}^{\prime}(1-x)=u_{2}(1-x)+b_{2} x
$$

This implies demand reduction: $-x u_{2}^{\prime}(1-x)>0$, so in equilibrium player 1 gets a quantity that is smaller than efficient (efficiency is where $u_{1}(x)=u_{2}(1-x)$ ).

To implement the optimal $x$, bidder 1 needs the clock phase to end when $v_{1}(x)=u_{2}(1-x)$. Therefore the following linear proxy strategy is ex post optimal against any $u_{2}$ parameterized by $a_{2}$ :

$$
v_{1}(x)=u_{1}(x)-b_{2} x=a_{1}-\left(b_{1}+b_{2}\right) x .
$$

Proposition 2 Suppose bidders 1 and 2 resolve indifferences in favor of making rivals pay more, and that furthermore bidder 1 restricts attention only to proxy strategies, while bidder 2 to strategies that do not cause excess supply in the clock phase. Then there is an ex post equilibrium in which 
bidder 1 uses the proxy strategy $v_{1}(x)=u_{1}(x)-b_{2} x$ in the clock phase, and bidder 2 maintains demand of 1 until dropping demand immediately to $1-x$ when $p=v_{1}(x)=u_{2}(1-x)$, and then both bidders are consistent in the final bid round.

\subsection{Properties of the Equilibrium with Predatory Player}

Allocation. In the equilibrium we described the allocation is skewed inefficiently in favor of player 2. In particular, the equilibrium allocation is:

$$
x_{1}^{*}=\frac{a_{1}-a_{2}+b_{2}}{b_{1}+2 b_{2}}=x_{1}^{*} \frac{b_{1}+b_{2}}{b_{1}+2 b_{2}}<x_{1}^{e},
$$

where $x_{1}^{e}$ is the efficient allocation just as in Section 5.3. Here the intuition is straightforward: given the demand submitted by the player 1 , the predatory player 2 wants to choose the same quantity as if she was bidding truthfully, whereas player 1 engages in defensive demand reduction.

Revenue. In equilibrium bidder 1 pays $x_{1}^{*} p^{*}$ while bidder 2 pays (assuming $\left.a_{1} \geq b_{1}+b_{2}\right) S_{1}(1)-$ $S_{1}\left(x_{c}\right)$. There are two opposing effects. First, compared to the truthful Vickrey payments, bidder 1 does not get any discount off the clock price for his inframarginal units. Second, bidder 1's reduced demand allows bidder 2 to pay less. After some algebra, revenue is equal to:

$$
R_{C C A}=a_{1}-\frac{1}{2}\left(\left(x_{1}^{*}\right)^{2}+1\right)\left(b_{1}+b_{2}\right)
$$

which can be above or below the truthful Vickrey revenue. For example, if $b_{1}=b_{2}$ and $a_{1}=a_{2}$ (so the efficient allocation is for both players to win half of the units), the demand reduction effect dominates and revenue is lower than in the truthful equilibrium. If $b_{1}=b_{2}$ but $a_{1} \gg a_{2}$ (so bidder 1 gets almost all units), the predatory effect dominates and revenues are higher than in the truthful equilibrium.

\section{Mutually Aggressive Behavior}

What happens if both bidders are predatory and attempt to push rival payments up toward the final clock prices? As we saw in the last section, bidders can raise rival's costs by demanding extra quantity in the clock phase, then sharply dropping demand to clear the market. However, it is difficult to develop an equilibrium theory with sharp predictions if bidders employ non-proxy strategies. 
Instead we take a more direct approach. We focus on proxy strategies, but assume that each bidder also has some ability to relax the revealed preference constraint on its final bids, and force its rival to pay closer to the final clock price for all units. This modeling approach is motivated by the features of CCA sales with multiple categories. Under the multi-category CCA rules that have been used in practice, bidders do in fact have a fair amount of flexibility to relax the final round revealed preference constraints without greatly distorting their clock phase bidding.

Specifically, we focus on (linear) proxy strategies in which bidder $i$ uses a proxy demand $v_{i}(x)=$ $A_{i}-B_{i} x$ in the clock phase, with $A_{i} \geq B_{i}>0$, and then in the final round submits marginal values

$$
s_{i}(x)=\left(1-\eta_{i}\right) v_{i}(x)+\eta_{i} p^{*}
$$

that are a linear combination of her clock value $v_{i}(x)$ and the final clock price $p^{*}$.

The parameter $\eta_{i} \in[0,1]$ captures the extent to which bidder $i$ is able to relax the local revealed preference constraints. If $\eta_{i}=0$, bidder $i$ is consistent. If $\eta_{i}>0$, bidder $i$ is able to increase her stated values in the final bid round toward the final clock price. In particular, because $v_{i}(x)$ is decreasing from $p^{*}$ above $x_{i}^{*}$, an increase in $\eta_{i}$ means that bidder $i$ 's final bid function is everywhere steeper, starting from the same bid for $x_{i}^{*}$. So an increase in $\eta_{i}$ increases the rival's total payment and marginal prices.

The behavior of the predatory bidder 2 in Section 6 is also captured in this model, by assuming that $\eta_{2}=1$. Indeed, the equilibrium described there will correspond to the one we will identify below, with $\eta_{1}=0$ and $\eta_{2}=1$.

A complete proxy strategy for bidder $i$ is described by $\left(A_{i}, B_{i}, \eta_{i}\right)$. As we did in Section 5 , we treat $\eta_{1}, \eta_{2}$ as parameters, and solve for an ex post equilibrium in choices of $\left(A_{i}, B_{i}\right)$. As in the above analysis, these equilibria will have the feature that $A_{i}$ varies with $a_{i}$ but $B_{i}$ does not.

\subsection{Proxy Best Responses}

We identify a strategy for bidder 1 that is an ex post best response, assuming that bidder 2 follows a linear proxy strategy $v_{2}$ with varying intercept, and final round strategy given by $\eta_{2}$.

Suppose bidder 1 uses the proxy demand $v_{1}(x)$. He will win $x$ units, where $x$ satisfies: ${ }^{21}$

$$
v_{1}(x)=v_{2}(1-x) .
$$

\footnotetext{
${ }^{21}$ We assume for now that the resulting equilibrium has interior quantities and prices, an assumption that can be later verified under our assumption that $\left|a_{1}-a_{2}\right|<\min \left\{b_{1}, b_{2}\right\}$.
} 
The ending clock price will be $p=v_{2}(1-x)$. So bidder 2's final bid will specify:

$$
s_{2}(z)=\left(1-\eta_{2}\right) v_{2}(z)+\eta_{2} v_{2}(1-x) \text { for } z \geq 1-x
$$

The final payment by bidder 1 will be ${ }^{22}$

$$
S_{2}(1)-S_{2}(1-x)=\left(1-\eta_{2}\right) \int_{1-x}^{1} v_{2}(z) d z+\eta_{2} x v_{2}(1-x)
$$

Once again, bidder 1 would like to choose the quantity that maximizes:

$$
U_{1}(x)-\left[S_{2}(1)-S_{2}(1-x)\right]
$$

A necessary condition for bidder 1 to be purchasing an optimal quantity given bidder 2's actual bid (and hence a necessary condition for bidder 1's behavior to be ex post optimal) is that bidder 1's marginal value for his last unit, $u_{1}(x)$, is just equal to his marginal payment for that unit. Bidder 1 's marginal payment for his $x$ th unit is

$$
\frac{d}{d x}\left\{S_{2}(1)-S_{2}(1-x)\right\}=v_{2}(1-x)+\eta_{2} B_{2} x
$$

Therefore a necessary condition for $x$ to be bidder 1's ex post optimal quantity is that

$$
u_{1}(x)=v_{2}(1-x)+\eta_{2} B_{2} x .
$$

Substituting the market-clearing condition (18) we get that the optimality condition (23) will hold for all $v_{2}$ and corresponding purchase quantities $x$ provided that:

$$
v_{1}(x)=u_{1}(x)-\eta_{2} B_{2} x
$$

Therefore bidder 1 has an ex post best response that involves following a linear proxy strategy for the clock phase with $A_{1}=a_{1}$ and $B_{1}=b_{1}+\eta_{2} B_{2}$.

\subsection{Proxy Equilibrium}

We now solve for an ex post equilibrium in linear proxy strategies. Since we already found that the best-response $A_{i}=a_{i}$, we need to only solve for the equilibrium $B_{i}$. Using the best response

\footnotetext{
${ }^{22}$ This assumes $s_{2}(z) \geq 0$ for $z \in(1-x, 1)$ which requires that $\eta_{i}^{\prime} s$ are not too high. The formula below for marginal price applies more generally.
} 
conditions $B_{i}=b_{i}+\eta_{j} B_{j}$, we obtain

$$
B_{i}=\left(b_{i}+\eta_{j} b_{j}\right) /\left(1-\eta_{i} \eta_{j}\right) .
$$

Defining

$$
\lambda_{i}=\eta_{j} B_{j}=\eta_{2} \frac{b_{2}+\eta_{1} b_{1}}{1-\eta_{1} \eta_{2}},
$$

allows us to describe the ex post equilibrium as follows:

Proposition 3 If bidders can relax the local revealed preference constraints in the final bid round, then for any $\eta_{1}, \eta_{2}$ with $\eta_{1} \eta_{2}<1$, there is an ex post equilibrium of the CCA in which each bidder $i$ uses a linear proxy strategy:

$$
\begin{aligned}
v_{i}(x) & =u_{i}(x)-\lambda_{i} x \\
\text { and } s_{i}(x) & =\left(1-\eta_{i}\right) v_{i}(x)+\eta_{i} p^{*},
\end{aligned}
$$

where $p^{*}$ is the final clock round price.

\subsection{Properties of the Equilibrium}

Bidding Behavior. When bidders are aggressive in their final bids to the point of bidding higher than their consistent final bids, the best response is to engage in demand reduction. Therefore in the mutually aggressive equilibrium, demand in the clock phase is lower and flatter (rotated in from $x=0$ ) than under truthful bidding:

$$
v_{1}(x)-u_{1}(x)=-\lambda_{1} x \leq 0 .
$$

This contrasts with the earlier model, where bidders tended toward being quiet in their final bids and the response was demand expansion in the clock phase.

Allocation and Revenue. Again, the equilibrium allocation and revenue generally differ from the truthful Vickrey outcomes. Consider the symmetric example (the extreme asymmetric case $\eta_{1}=0$ and $\eta_{2}=1$ is outcome-equivalent to the predatory player model discussed in the previous section). That is, suppose $\eta_{1}=\eta_{2}=\eta$ and $b_{1}=b_{2}=b$, which implies $\lambda_{1}=\lambda_{2}=\frac{\eta}{1-\eta} b$. Then the allocation is distorted toward $1 / 2$ compared to the efficient allocation $x_{1}^{e}$ :

$$
x_{1}^{*}=\frac{1}{2} \eta+(1-\eta) x_{1}^{e} .
$$


As for revenue, in the parameter range where $s_{i}(x) \geq 0$ for all $x$, we have:

$$
\begin{aligned}
R_{C C A} & =S_{1}(1)-S_{1}\left(x_{1}^{*}\right)+S_{2}(1)-S_{2}\left(1-x_{1}^{*}\right) \\
& =\frac{a_{1}+a_{2}}{2}-\frac{1}{4} b \frac{\eta-3}{\eta-1}-\frac{1}{4}\left(a_{1}-a_{2}\right)^{2} \frac{(\eta-1)^{2}}{b} .
\end{aligned}
$$

Under our maintained assumption $\left|a_{1}-a_{2}\right|<b$, the revenue is decreasing in $\eta$ (so despite the more aggressive final round bidding when $\eta>0$, revenues are lower than under truthful bidding since the demand reduction effect dominates).

\section{Conclusion}

Our analysis highlights several properties of the combinatorial clock auction. First, the activity rules used to encourage truthful bidding mean that a bidder's final round bids may have no effect at all on her own payoff. Yet if bidders do not increase their final bids to levels consistent with their expressed demand in the clock phase (and they have no strict incentive to do so), this leads to price discounts and incentives for demand expansion in the initial clock phase. Even in the very simple model we considered, the result is a wide range of ex post equilibria, with no guarantee of an efficient allocation or truthful Vickrey prices.

Second, bidders may care not just about their own payoff, but about their outcome relative to rival bidders. At first glance, this seems to create an incentive for bidders simply to raise their final bids to the correct levels, generating an efficient outcome. However, we have shown that this is not the case. Instead, if one bidder behaves in a truthful manner, its rival will have both the incentive and the opportunity to behave in predatory fashion, keeping demand high during the clock phase in order to drive up the payment of the first bidder. At the extreme, the first bidder's average payment will equal its marginal payment for its last unit. If the first bidder understands this, he will reduce demand, leading again to an inefficient equilibrium outcome with predation.

Third, we have argued that if all bidders attempt to drive up rival prices, the final prices may resemble clock prices, creating incentives for demand reduction. So once again, there is no particular reason to expect an efficient outcome or truthful Vickrey prices. We modeled this last case in a somewhat stylized way to get clear results. If bidders all attempt to keep demand high during the clock phase to raise rival costs, it seems possible that information revelation in the clock phase may be hindered.

A loose way to summarize these points is that the CCA relies on bidders "doing the right thing" in making decisions about which they have no direct financial incentives. Unfortunately, 
doing the right thing is subtle. Bidders must raise their final round bids so that the revealed preference activity constraints bind, but not take actions in the clock phase to purposely relax these constraints! Our examples show how, if bidders are not sufficiently aggressive, or are overly aggressive, incentives for demand expansion and/or reduction appear and outcomes need not be efficient, even if behavior is completely understood and bidders play minimally strategic ex post equilibria.

Our analysis makes several simplifying assumptions. We mostly restrict attention to proxy strategies in which bidders do not condition their bidding on rival behavior. With contingent strategies, our model admits many more equilibria. These include highly collusive equilibria in which bidders split the market and drive each other's prices to zero, using the threat of aggressive final bids to punish deviations. However, these types of equilibria also arise in traditional clock auctions and are not special to the CCA. ${ }^{23}$ Our assumptions also implied that the clock phase ends with market clearing. If bidders can drop demand discontinuously, the clock phase may end with some units unallocated. This can be useful for package bidders who want to avoid exposure problems - a potentially important benefit of the CCA that is not captured in our model ${ }^{24}$ — but also creates new strategic possibilities. ${ }^{25}$

Another important point is that while our analysis shows some limitations of the CCA, other multi-item auction designs have their own drawbacks. Ausubel and Cramton (2002) have shown in great generality that uniform price auctions create incentives for demand reduction and inefficiency. Ausubel and Milgrom (2006) have catalogued problems with the sealed-bid Vickrey auction, such as incentives for collusion, and the fact that Vickrey outcomes may lie outside the core. Our analysis points to a further problem with the Vickrey auction that we view as equally serious. If bidders understand that the allocation will almost certainly lie in a particular range (the relevant situation in most radio spectrum auctions), their incentives to bid truthfully outside of this range may be very weak despite these bids potentially being crucial for pricing. Indeed, one way to view our paper is that we have simply formalized this point for a particular dynamic implementation of the Vickrey auction.

A final question is whether a different CCA activity rule could resolve some of the issues we have

\footnotetext{
${ }^{23}$ In fact, Riedel and Wolfstetter (2006) show that the simultaneous multiple round auction with complete information has an essentially unique subgame perfect equilibrium in which the bidders immediately demand their efficient allocation and the auction ends.

${ }^{24}$ See Bulow, Levin and Milgrom (2009) and Cramton (2012) for discussions of the exposure problem faced by package bidders in traditional clock auctions.

${ }^{25}$ If there are unallocated units in the final round of the CCA, bidders will have an incentive to bid truthfully for these units, but not necessarily for units that they cannot possibly win. The ability to create excess supply also creates new opportunities for predation, as a predatory bidder can potentially drop its demand to zero and subsequently raise its rival's payment even higher than contemplated in Section 6.
} 
flagged, and lead to a successful dynamic Vickrey implementation. A recent and very interesting paper by Ausubel and Baranov (2013) suggests one possibility, which is to require that clock phase bids satisfy GARP, and then to use an algorithm based on the Afriat inequalities to fill in the final bids. In our setting, this would amount to requiring global rather than local revealed preference. This would resolve the quiet bidding problems illustrated in Section 5, but not the predatory bidding problems illustrated in Sections 6 and $7 .{ }^{26}$ Nevertheless, this proposal and others seem to merit further investigation.

\section{References}

Ausubel, Lawrence M. (2004), "An Efficient Ascending-Bid Auction for Multiple Objects," American Economic Review, 94(5), 1452-1475.

Ausubel, Lawrence M. and Oleg Baranov (2010) "Core-Selecting Auctions with Incomplete Information," University of Maryland Working Paper.

Ausubel, Lawrence M. and Oleg Baranov (2013) "An Enhanced Combinatorial Clock Auction," University of Maryland Working Paper.

Ausubel, Lawrence M. and Peter Cramton (2011), "Activity Rules for the Combinatorial Clock Auction," University of Maryland Working Paper.

Ausubel, Lawrence M., Peter Cramton and Paul Milgrom (2006), "The Clock-Proxy Auction: A Practical Combinatorial Auction Design," in Peter Cramton, Yoav Shoham and Richard Steinberg (eds.) Combinatorial Auctions, MIT Press, Chapter 5, pp. 115-138.

Ausubel, Lawrence M. and Paul Milgrom (2006), "The Lovely but Lonely Vickrey Auction," in Peter Cramton, Yoav Shoham and Richard Steinberg (eds.) Combinatorial Auctions, MIT Press, Chapter 1, pp. 17-40.

Beck, Marissa and Marion Ott (2013) "Incentives for Overbidding in Minimum-Revenue CoreSelecting Auctions," Stanford University Working Paper.

Bichler, Martin, Pasha Shabalin, and Jürgen Wolf (2013), "Do Core-Selecting Combinatorial Clock Auctions Always Lead to High Efficiency? An Experimental Analysis of Spectrum Auction Designs," Experimental Economics, 16(4), pp. 511-545.

Bulow, Jeremy, Jonathan Levin and Paul Milgrom (2009), "Winning Play in Spectrum Auctions," Stanford University Working Paper.

\footnotetext{
${ }^{26}$ A similar point about incentives for aggressive bidding also would apply in our setting to the Ausubel (2004) clinching auction, which is an alternative dynamic VCG implementation in our setting. Ausubel, Cramton and Milgrom (2006) also proposed a relaxed version of revealed preference, which forces bidders to increase their final clock rounds bids in order to "guarantee" their package from the last clock round. However, this rule also doesn't appear to provide strong incentives to submit "correct" bids for losing packages.
} 
Cramton, Peter (2008a), "A Review of the 10-40 GHz Auction," Office of Communications, United Kingdom.

Cramton, Peter (2008b), "A Review of the L Band Auction," Office of Communications, United Kingdom.

Cramton, Peter (2009), "Auctioning the Digital Dividend," Communications Regulation in the Age of Digital Convergence: Legal and Economic Perspectives. Ed. Jan Kramer and Stefan Seifert. Karlsruhe, Germany: Karlsruhe Institute of Technology.

Cramton, Peter (2013), "Spectrum Auction Design," Review of Industrial Organization, 42(2), pp. 161-190.

Day, Robert and Paul Milgrom (2008), "Core-Selecting Package Auctions," International Journal of Game Theory, 36, pp. 393-407.

Day, Robert. and S. Raghavan (2007) "Fair Payments for Efficient Allocations in Public Sector Combinatorial Auctions," Management Science, 53, pp. 1389-1406.

Erdil, Aytek and Paul Klemperer (2009). "A New Payment Rule for Core-Selecting Auctions," Journal of the European Economic Association, 8, 537-547.

Goeree, Jacob and Yuanchuan Lien (2013). "On the Impossibility of Core-Selecting Auctions," forthcoming in Theoretical Economics.

Janssen, Maarten and Vladimir Karamychev (2013), "Gaming in Combinatorial Clock Auctions," Tinbergen Institute Discussion Paper 13-027/VII.

Jewitt, Ian and Zhiyun Li (2008), "Report on the 2008 UK 10-40 GHz Spectrum Auction," Office of Communications, United Kingdom.

Klemperer, Paul (2004), Auctions: Theory and Practice, Princeton University Press.

Knapek, Stephan and Achim Wambach (2012), "Strategic Complexities in the Combinatorial Clock Auction," CESifo Working Paper 3983.

Kyle, Albert S. (1989), "Informed Speculation With Imperfect Competition," Review of Economic Studies, 56(3), 317-355.

Milgrom, Paul (2004), Putting Auction Theory to Work, Cambridge University Press.

Milgrom, Paul (2007), "Package Auctions and Exchanges," Econometrica 75: 935-965.

Morgan, John, Ken Steiglitz and George Reis (2003), "The Spite Motive and Equilibrium Behavior in Auctions," Contributions to Economic Analysis 63 Policy, 2(1), Article 5.

Riedel, Frank and Elmar Wolfstetter (2006), "Immediate demand reduction in simultaneous ascending-bid auctions: a uniqueness result," Economic Theory, 29(3), pp. 721-726.

Salant, David (2013), A Primer on Auction Design, Management, and Strategy, mimeo, Toulouse School of Economics.

Vives, Xavier. (2011), "Strategic Supply Function Competition With Private Information," Econometrica, 79: 1919-1966 


\section{Figure 1. Activity Rule and Final Bid Options}

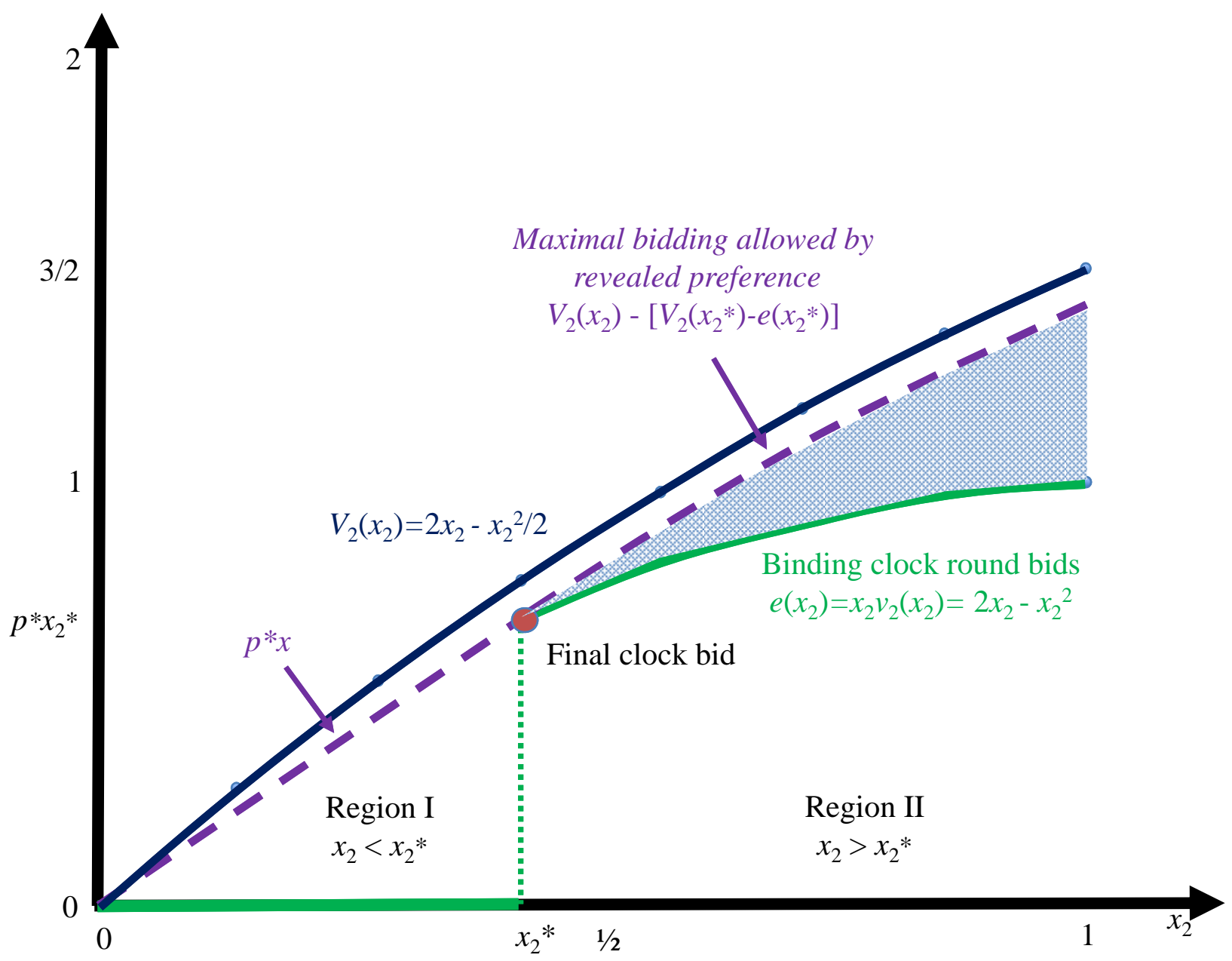

Figure shows the flexibility that bidder 2 has in choosing final bids in the final bid round. The lower curve shows bidder 2's clock phase bids, which places a lower bound on her final bids. The dashed curve is the upper bound for final bids (assuming bidder 2 leaves her last clock bid unchanged). The top curve is the valuation that guides bidder 2's clock round bidding. The dashed upper bound is parallel to this curve for quantities above $x_{2}{ }^{*}$. 


\section{Figure 2. Best Responses to Quiet and Consistent Bidding}

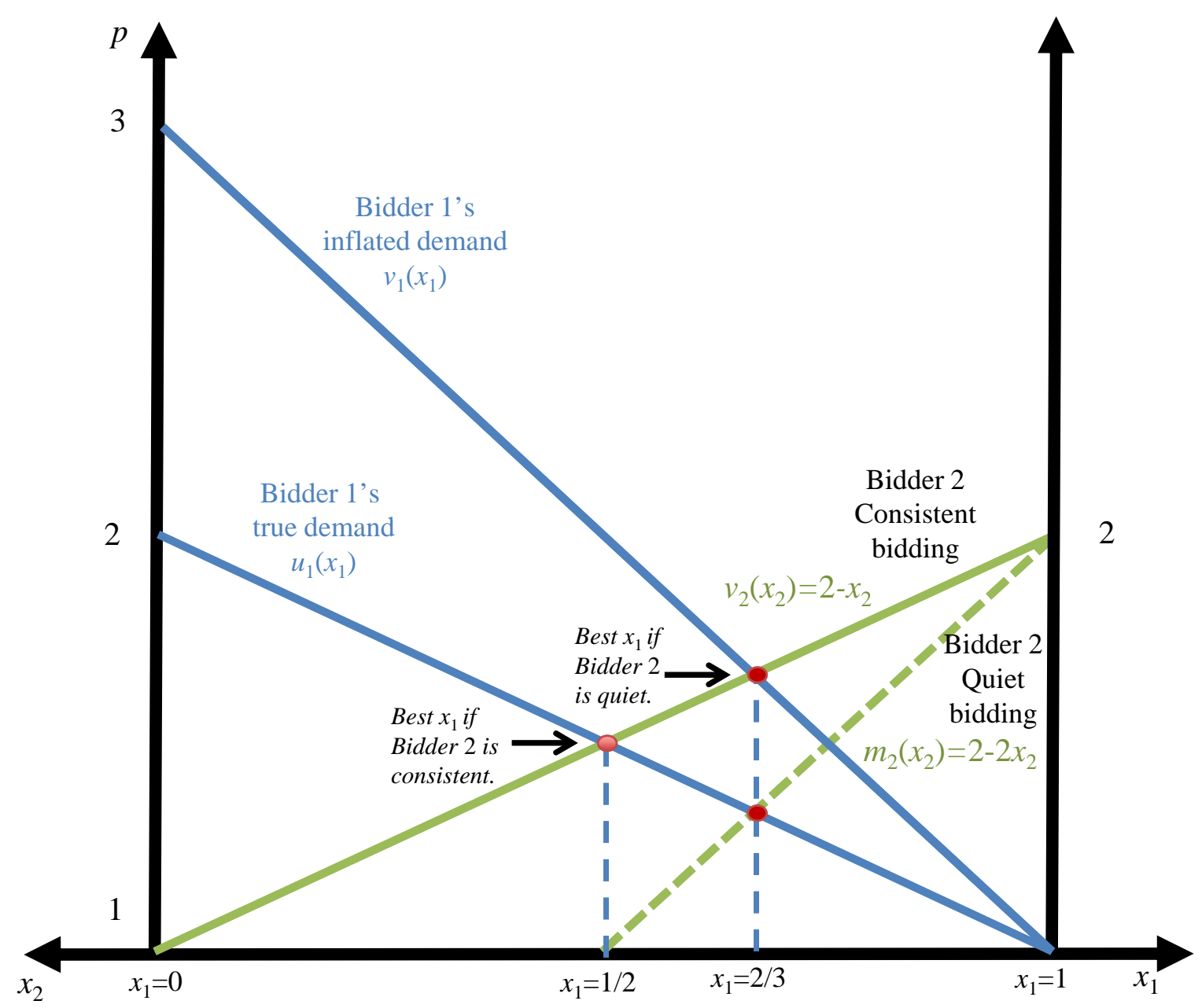

Figure shows possible best responses for bidder 1 in response to bidder 2 using a quiet or consistent strategy. If bidder 2 is consistent, bidder 1 faces marginal prices equal to clock prices, and optimally intersects his clock demand with bidder 2's clock demand. If bidder 2 is quiet, bidder 1's marginal price is lower than the clock price. The best response is to purchase a quantity at which bidder 1's marginal value equals bidder 2's marginal revenue, which can be done by inflating demand in the clock phase, as shown in the figure. 


\section{Figure 3. Predatory Clock Phase Bidding to Raise Rival Prices}

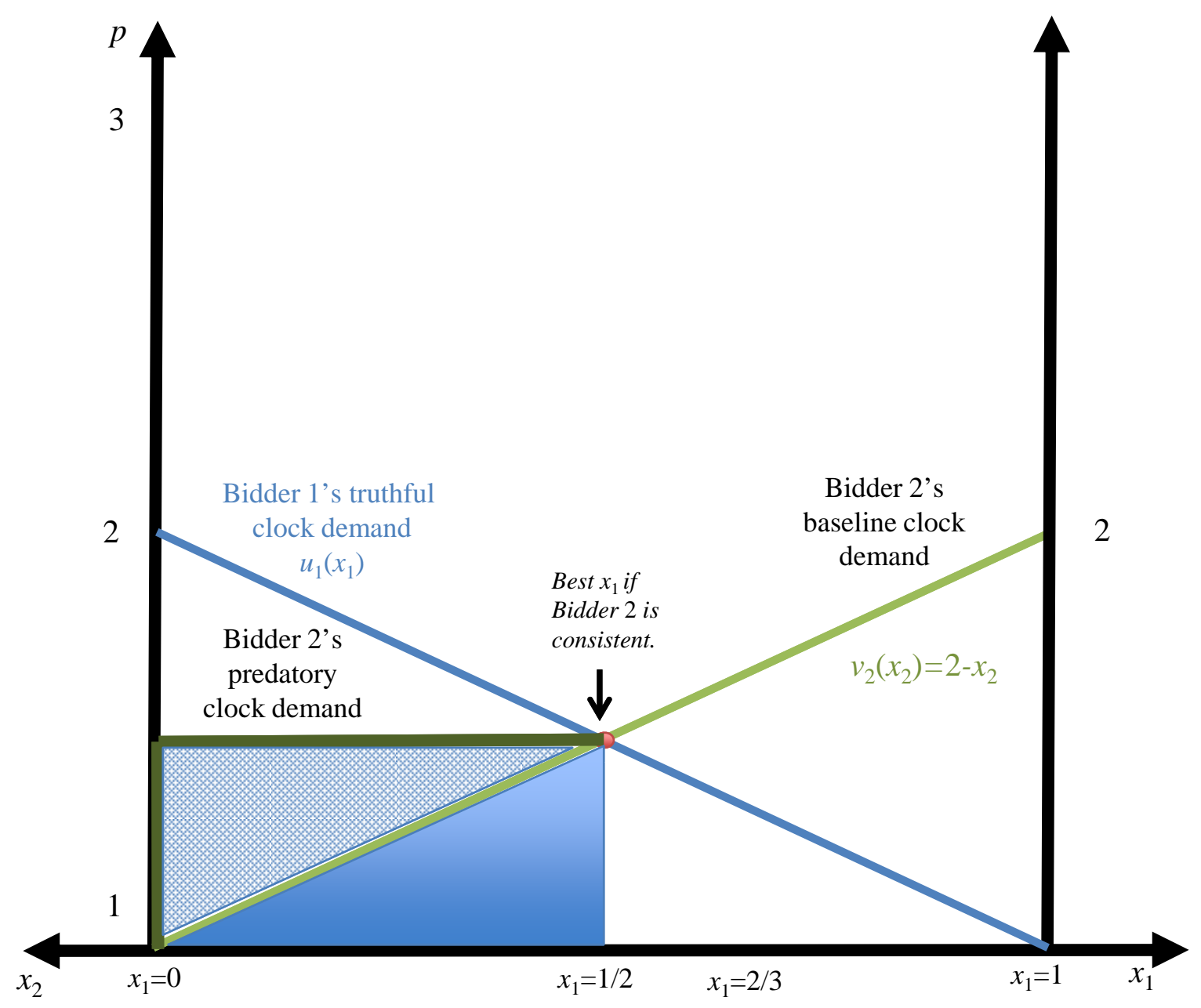

Figure shows bidder 2's baseline clock demand, and bidder 1's truthful demand, which is a best response if bidder 2 is consistent in the final round bid. In this case, bidder 1 expects to pay the shaded area under bidder 2's clock phase demand curve. However, if bidder 2 maintains a higher (predatory) clock demand and submits final bids which are consistent with this higher demand, bidder 1 will have to pay both the shaded area and the dotted area. 


\section{Figure 4. Final Bids by Vodafone in the UK $800 / 2600 \mathrm{MHz}$ Auction}

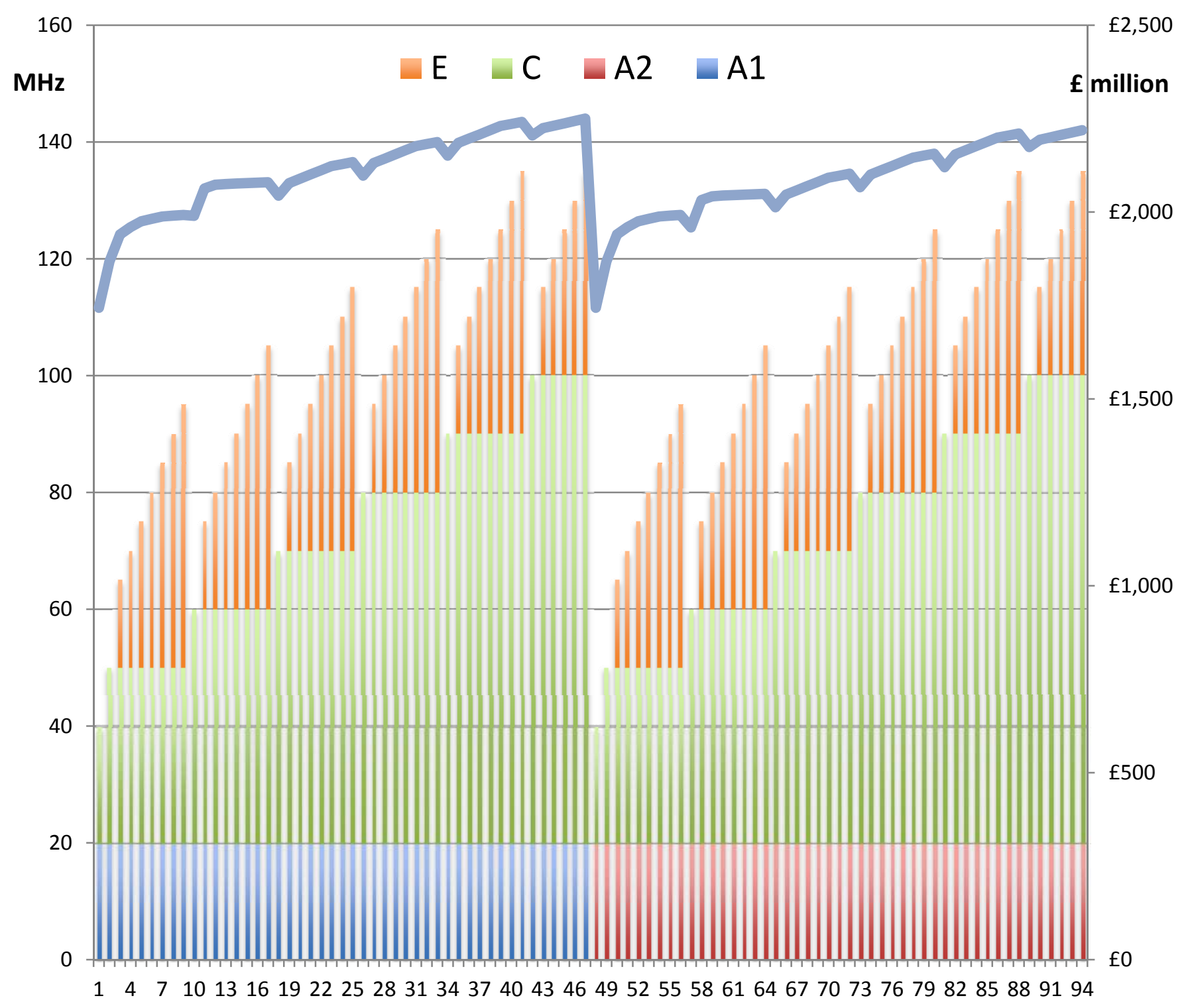

Figure shows all of Vodafone's final bids in the UK 800/2600 auction. The solid bars show the composition of each bid in terms of the $\mathrm{MHz}$ demanded in each of the four color-coded bands (E, C, A1 and A2). The solid line above shows the value of the bid in GBP (£). Vodafone's bids place consistent value on spectrum increments corresponding to clock behavior. 


\section{Figure 5. Final Bids by Telefonica in the UK $800 / 2600 \mathrm{MHz}$ Auction}

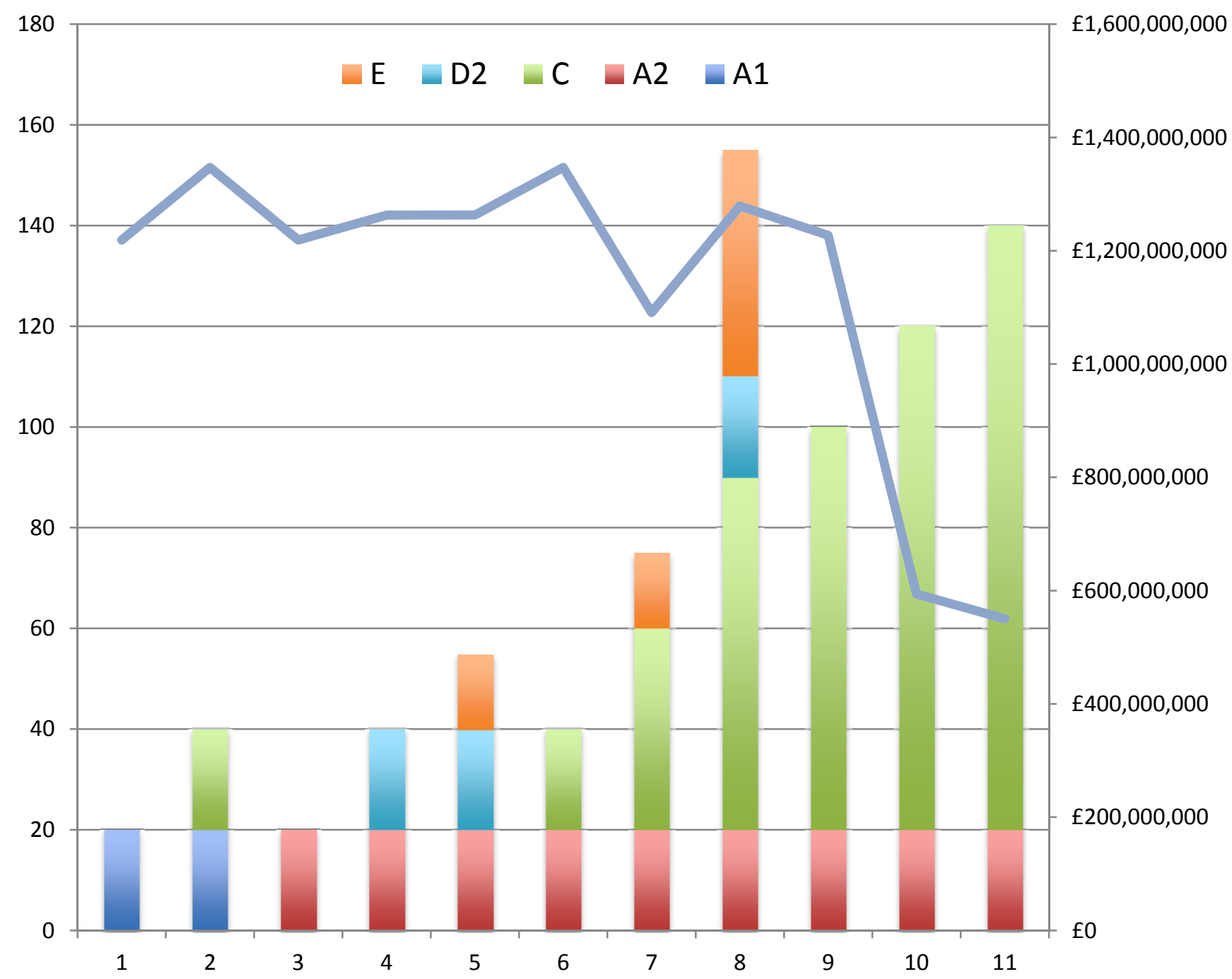

Figure shows all of Telefonica's final bids in the UK 800/2600 auction. The solid bars show the composition of each bid in terms of the $\mathrm{MHz}$ demanded in each of the four color-coded bands (E, C, A1 and A2). The solid line above shows the value of the bid in GBP ( $£$ ). Telefonica submitted very few serious bids in the sealed bid round, with much smaller incremental valuations than it revealed during the clock phase, closer to a quiet strategy. 


\section{Figure 6. Bidder Incentives in a CCA Equilibrium}

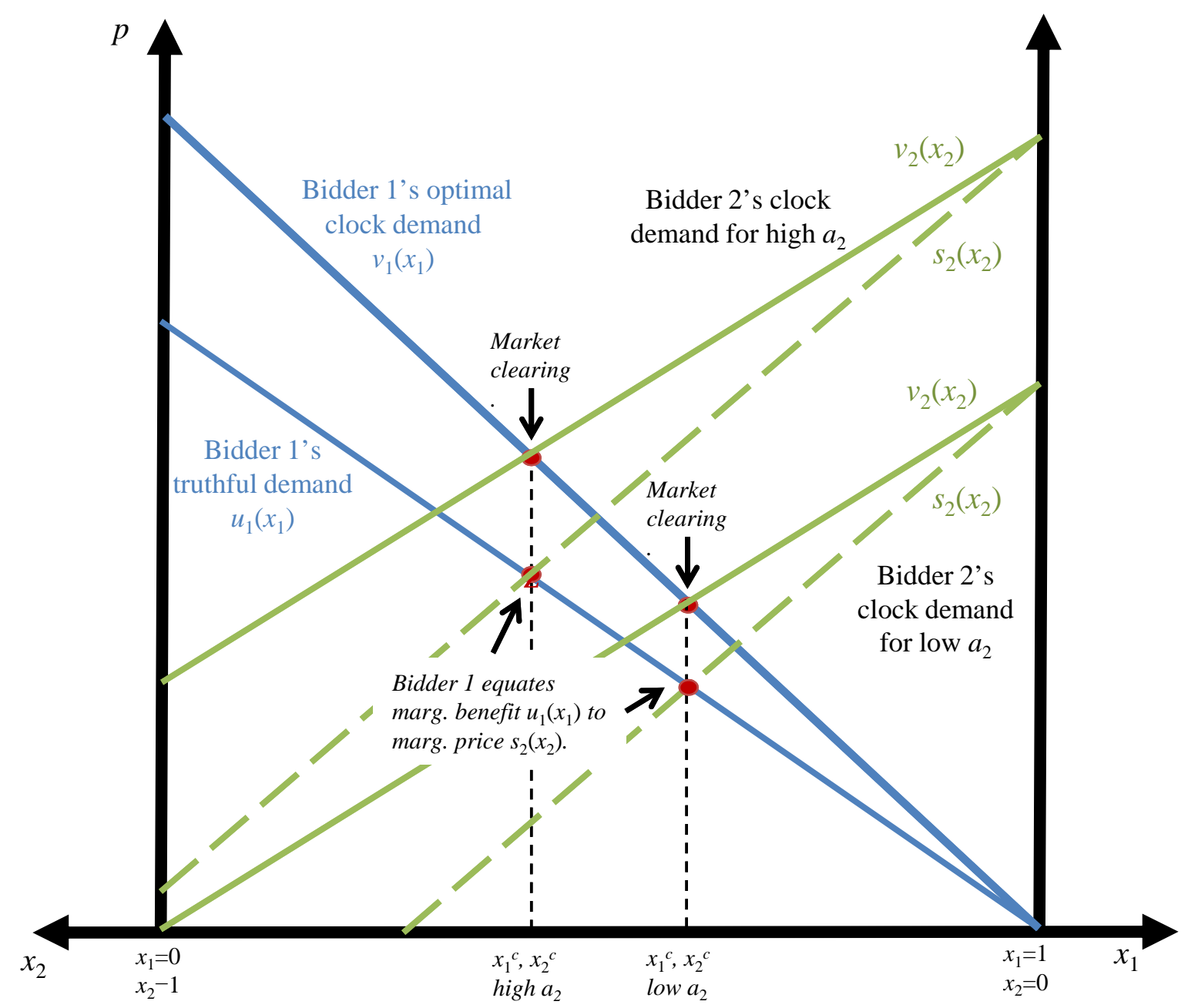

Figure shows the derivation of bidder 1's best response given that bidder 2 is using her equilibrium strategy. Bidder 1's optimal demand inflates his true demand. His optimal demand is chosen so that for any realization of bidder 2's demand, the clock phase ends (market clearing) at the allocation where bidder 1's true marginal valuation just equals his marginal price, which he correctly anticipates will be set by bidder 2's final bid. 


\section{Figure 7. Clock and Final Bids with Market Clearing}

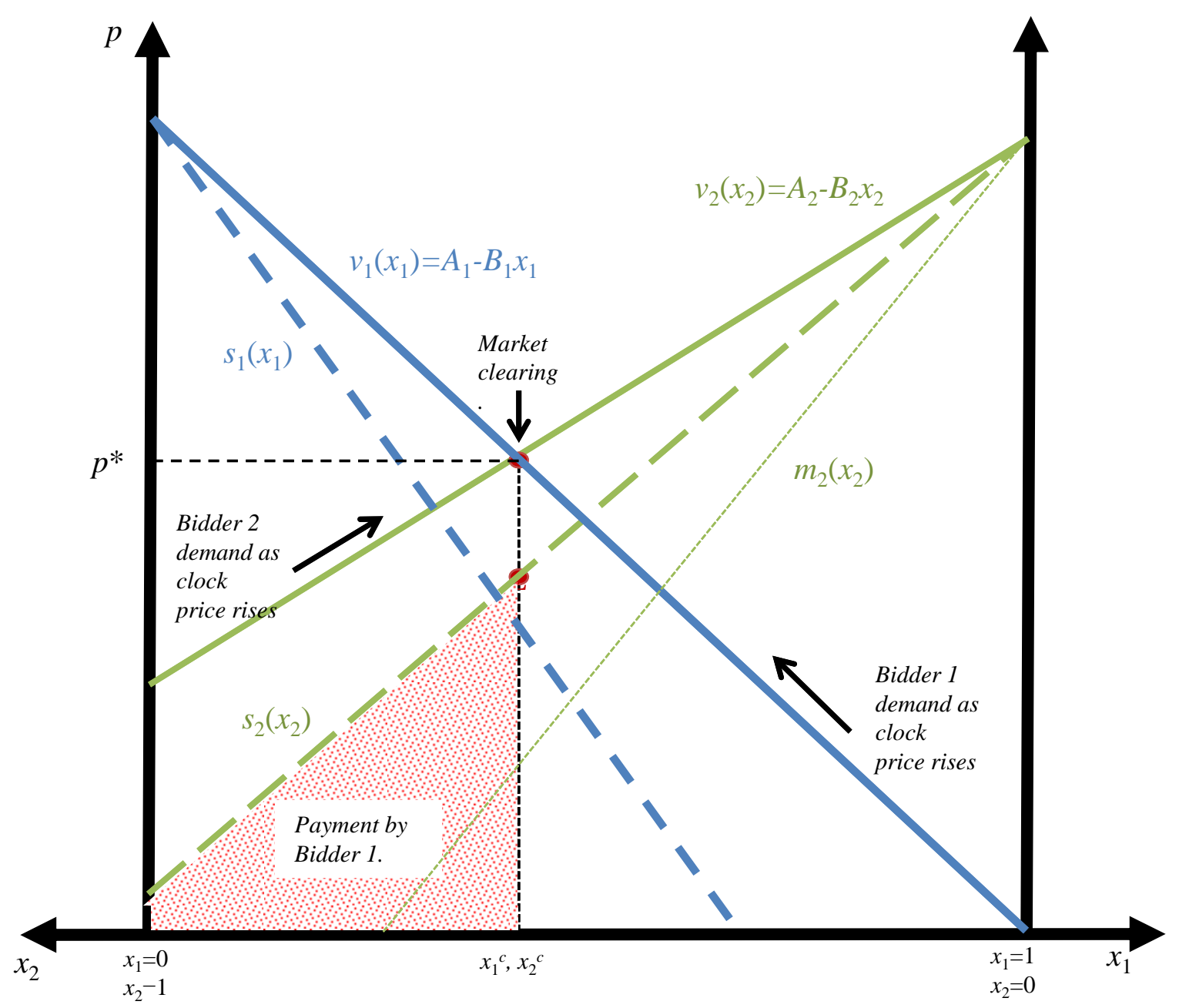

Figure shows equilibrium behavior for a single realization of values. The solid lines represent the equilibrium clock demand curves of the bidders; the dashed lines the final round demand curves. The thin line for bidder 2 is her clock round marginal revenue curve. Her final demand curve is intermediate between her clock demand and clock marginal revenue - so she bids partway between quiet and consistent. 